\title{
Expansion of the phosphatidylethanolamine binding protein family in legumes: a case study of Lupinus angustifolius L. FLOWERING LOCUS T homologs, LanFTc1 and LanFTC2
}

\author{
Michał Książkiewicz ${ }^{1 *}$ (D), Sandra Rychel ${ }^{1}$, Matthew N. Nelson ${ }^{2,3,4}$, Katarzyna Wyrwa', Barbara Naganowska ${ }^{1}$
} and Bogdan Wolko ${ }^{1}$

\begin{abstract}
Background: The Arabidopsis FLOWERING LOCUS T (FT) gene, a member of the phosphatidylethanolamine binding protein (PEBP) family, is a major controller of flowering in response to photoperiod, vernalization and light quality. In legumes, FT evolved into three, functionally diversified clades, FTa, FTb and FTc. A milestone achievement in narrow-leafed lupin (Lupinus angustifolius L.) domestication was the loss of vernalization responsiveness at the $K u$ locus. Recently, one of two existing L. angustifolius homologs of FTc, LanFTC1, was revealed to be the gene underlying $\mathrm{Ku}$. It is the first recorded involvement of an FTC homologue in vernalization. The evolutionary basis of this phenomenon in lupin has not yet been deciphered.

Results: Bacterial artificial chromosome (BAC) clones carrying LanFTc1 and LanFTc2 genes were localized in different mitotic chromosomes and constituted sequence-specific landmarks for linkage groups NLL-10 and NLL-17. BAC-derived superscaffolds containing LanFTc genes revealed clear microsyntenic patterns to genome sequences of nine legume species. Superscaffold-1 carrying LanFTC1 aligned to regions encoding one or more FT-like genes whereas superscaffold-2 mapped to a region lacking such a homolog. Comparative mapping of the L. angustifolius genome assembly anchored to linkage map localized superscaffold- 1 in the middle of a $15 \mathrm{cM}$ conserved, collinear region. In contrast, superscaffold-2 was found at the edge of a $20 \mathrm{cM}$ syntenic block containing highly disrupted collinearity at the LanFTc2 locus. 118 PEBP-family full-length homologs were identified in 10 legume genomes. Bayesian phylogenetic inference provided novel evidence supporting the hypothesis that whole-genome and tandem duplications contributed to expansion of PEBP-family genes in legumes. Duplicated genes were subjected to strong purifying selection. Promoter analysis of FT genes revealed no statistically significant sequence similarity between duplicated copies; only RE-alpha and CCAAT-box motifs were found at conserved positions and orientations.

(Continued on next page)
\end{abstract}

\footnotetext{
* Correspondence: mksi@igr.poznan.pl

${ }^{1}$ Institute of Plant Genetics of the Polish Academy of Sciences, Strzeszyńska

34, 60-479 Poznań, Poland

Full list of author information is available at the end of the article
} 
(Continued from previous page)

Conclusions: Numerous lineage-specific duplications occurred during the evolution of legume PEBP-family genes. Whole-genome duplications resulted in the origin of subclades FTa, FTb and FTc and in the multiplication of FTa and FTb copy number. LanFTCl is located in the region conserved among all main lineages of Papilionoideae. LanFTC1 is a direct descendant of ancestral FTC, whereas LanFTc2 appeared by subsequent duplication.

Keywords: Lupinus angustifolius, Genomics, DNA sequencing, Flowering locus T, Phosphatidylethanolamine binding protein, Synteny, Duplication, BAC-FISH

\section{Background}

Transition from vegetative to reproductive growth depends on many environmental factors including photoperiod, light quality and temperature. The key control point where these external cues converge is the transcriptional regulation of FLOWERING LOCUS T (FT) gene [1]. FT belongs to phosphatidylethanolamine binding protein (PEBP) family, a very old group of proteins, widely distributed in the tree of life $[2,3]$. The plant representatives of the PEBP family constitute three subfamilies, FLOWERING LOCUS T (FT)-like, TERMINAL FLOWER1 (TFL1)-like, and MOTHER OF FT AND TFL1 (MFT)-like [4]. FT protein was evidenced as a major component of florigen, the molecular signal that triggers the transition to flowering [5]. The promoter and intronic regions of $F T$ carry all the elements that are necessary to alter $F T$ expression in response to photoperiod and vernalization, and consequently, to trigger flowering [6]. In the genome of Arabidopsis thaliana only two homologs of this gene exist, $F T$ and TWIN SISTER OF FT (TSF), and are very similar to each other ( $\sim 83 \%$ of coding sequence identity) [7]. In legumes, the number of FT homologs is higher, and they were grouped into three subclades FTa, FTb and FTc [8]. Typically, when multiple copies of the same gene appear in the genome, they acquire different functions by the processes of pseudogenization, subfunctionalization, or neo-functionalization $[9,10]$. Such a phenomenon has also been observed in the legume $F T$ subfamily. The $M$. truncatula FTa1 gene is associated with vernalization responsiveness and early flowering, whereas $F T b$ is considered to be involved in the photoperiod pathway $[8,11]$. In G. max, a species that does not require vernalization for flowering induction, the photoperiod response is maintained by two genes classified as $F T a$ and $F T c$ [8, $11,12]$. In the narrow-leafed lupin genome the whole $F T b$ subclade is absent and vernalization responsiveness is mediated by a gene from the FTc subclade [13]. $L$. angustifolius is the first legume species with its vernalization pathway anchored in the $F T c$ gene and as such is a very useful model for understanding the evolution of $F T$ homologs in this lineage. The uniqueness of the narrow-leafed lupin (so far) implies that phylogenetic inference based on model legumes is not representative for the genus Lupinus and, therefore, deciphering of evolutionary pathways require involvement genomic data from this species.

Lupins are valuable crops, appreciated as sources of protein for food and feed, as well as plants improving soil, enhancing yields and increasing economic payback for the succeeding crops in rotations. Narrow-leafed lupin (Lupinus angustifolius L.), as the most widelygrown lupin crop, has become the reference species for the genus Lupinus and more generally for the large genistoid clade. It has been the subject of cytological and molecular studies because of its relatively low chromosome number $(2 \mathrm{n}=40)$ and small genome size $(2 \mathrm{C}=1.89 \mathrm{pg})$, compared with other lupins [14]. Linkage maps with microsatellite-anchored fragment length polymorphisms [15], gene-based sequence tagged site (STS) markers [16] as well as consensus maps with both types of markers [17-19] were constructed. The current reference linkage map [17] contains 1475 markers of which 827 were sequenced. Bacterial artificial chromosome (BAC) libraries of the nuclear genomes were developed for two L. angustifolius cultivars: Polish cv. Sonet [20] and Australian cv. Tanjil [21]. An average insert size of both libraries is $\sim 100 \mathrm{~kb}$ whereas the genome coverage is estimated as 6 and 12, respectively. $\mathrm{BAC}$ analysis and cytogenetic experiments resulted in integration of all linkage groups with the corresponding chromosomes, as well as in identification of several gene-rich regions [22-27]. BAC-derived gene sequences enabled phylogenetic studies of particular gene families [26]. A specific bioinformatic pipeline has been developed to accelerate the analysis and support annotation of lupin sequence data [28]. Recently, draft assemblies were released, spanning about $45-50 \%$ of the L. angustifolius genome $[17,29]$. The genome sequence length for cv. Sonet was estimated as $924 \mathrm{Mbp}$ using flow cytometry [14] or 1037-1153 Mbp based on the K-number/ peak depth model calculation $[17,29]$. The opportunities for gene search and comparative mapping were greatly enhanced by the release of comprehensive transcriptome assembly, derived from sequencing of different narrowleafed lupin tissue types and anchored in the reference 
linkage map [17]. The recent developments in next generation sequencing techniques have considerably accelerated the progress in legume genomics in general. Up to now, the high quality genome sequences of nine Fabaceae species have been published: Arachis duranensis, A. ipaensis [30], Cajanus cajan [31], Cicer arietinum [32], Glycine max [33], Lotus japonicus [34], Medicago truncatula [35], Phaseolus vulgaris [36] and Vigna radiata [37]. These species represent main clades of Papilionoideae: dalbergioids (Arachis), genistoids (Lupinus), millettioids (Cajanus, Glycine, Phaseolus, Vigna), robinioids (Lotus), and the inverted repeat-lacking clade (Medicago). Comparative genomic studies between $L$. angustifolius and G. max identified a high level of microsynteny in the gene-rich regions. Not only was the gene nucleotide sequence conserved, but also the order and orientation of particular genes in syntenic blocks [23, 24, 26].

The synteny-based approach was applied to identify a gene underlying locus $\mathrm{Ku}$, conferring thermoneutrality of L. angustifolius, i.e. removing the need for vernalization to promote flowering. This natural dominant mutation was observed in Western Australia as an early flowering offtype in a field of the late flowering cultivar Borre [38]. Ku resulted in advancing flowering by $2-5$ weeks and therefore was widely introduced to cultivars in Europe and Australia [39]. It was a key advance in that it provided adaptation to major growing areas with light acidic soils in temperate and warmer climatic zones. One of FLOWERING LOCUS T (FT)-derived markers, dFTc, was localized directly in the $K u$ locus with no trace of recombination event between marker and the trait [18]. Such an observation strongly justified further investigation of this gene as a candidate gene for $K u$. Very recently, it was revealed that two homologs of $F T c$ are present in L. angustifolius genome, named as LanFTc1 and LanFTc2. Gene expression profiling of these genes after prolonged exposure to cold temperatures demonstrated that LanFTc1 is involved in the vernalization independence, whereas LanFTc2 is not [13]. As the L. angustifolius genome appears to have undergone whole genome duplication (WGD) events [18, 40], the question arises whether and to what extent WGD shaped the evolution of $F T$ and other PEBP-family genes in this species.

Here, recently developed legume genomic resources were enlisted to survey the $L$. angustifolius genome regions carrying both LanFTc genes. LanFTc BAC clones were physically localized in $L$. angustifolius chromosomes using fluorescence in situ hybridization. Sequenced BACs were mapped to the L. angustifolius genome scaffolds to form consensus sequences which were further used for functional annotation and microsynteny search across the legume family. Linkage groups carrying LanFTc genes, supplemented with sequence-defined markers, were aligned to the preliminary genome sequence of the species and then exploited for identification of cross genera large, chromosome-scale blocks of collinearity. Nucleotide and protein multiple alignment and protein-based Hidden Markov Model gene prediction were subsequently applied to retrieve PEBP-family sequences from sequenced legume genomes. Bayesian inference of phylogeny was performed to assign PEBP-family sequences to appropriate subclades and to track evolution of particular homologs.

\section{Results}

\section{Chromosomal localization of LanFTc genes}

In the narrow-leafed lupin genome two copies of FTc homolog exist, LanFTc1 assigned to linkage group NLL-10 and LanFTc2 localized in NLL-17 [13]. Based on the sequence annotation, BAC clones carrying these genes were grouped into two contigs, 12 in contig 1 carrying LanFTc1 and 5 in contig 2 carrying LanFTc2. To visualize their chromosomal localization, all clones derived from these contigs were used as molecular probes and subjected to fluorescent in situ hybridization (BAC-FISH) to mitotic chromosomes of $L$. angustifolius. Five BACs from contig 1 (006C24, 015A19, 075P11, 082M07, 133N08) and one from contig 2 (042F24) gave single locus signals, whereas the remaining ones produced repetitive signals dispersed over numerous chromosomes. BAC clones hybridizing to single loci were used in various combinations in two-colored BAC-FISH experiments. To verify BAC localization, available chromosome-specific landmarks for linkage groups NLL-10 (clones 057K22 and 077C13) and NLL-17 (003B18 and 136C16) [23-25] were included in the survey. In total, $15 \mathrm{BAC}$ pairs were tested: 5 for contig 1 itself, 4 for contig 1 vs 2 , and 6 for contig vs linkage group (Table 1). BAC clones originating from the same contig or linkage group produced overlapping signals on one pair of homologous chromosomes whereas those from different contigs or linkage groups yielded single locus signals on two different chromosome pairs (Fig. 1). BAC clones which hybridized to single loci on mitotic chromosomes were considered as new cytogenetic markers. Together with those already published [23-27], they constituted physical anchors for the integration of genetic and cytogenetic maps of the L. angustifolius genome.

\section{Anchoring L. angustifolius genome scaffolds to the updated reference linkage map}

The reference map of the narrow-leafed lupin genome [17] was supplemented with recently published BAC-end sequence (BES)-derived markers from contig 1 (133N08_5, 080K01_3D, 008L15_5, 082M07_3, 130O02_5) and 2 (137O24_5，071N21_3，042F24_5，092M12_5，042F24_3) [13]. Moreover, the existing BES markers from linkage groups NLL-10 (077C13_3, 057K22_3F2) and NLL-17 (107M16_3, 111G03_5, 024F12_5D, 111L22_5, 141C03_5D, 
Table 1 Co-localization of cytogenetic markers for both contigs and L. angustifolius linkage groups NLL-10 and NLL-17

\begin{tabular}{|c|c|c|c|c|c|c|}
\hline & $\begin{array}{l}006 C 24, \\
\text { contig } \\
1\end{array}$ & $\begin{array}{l}015 \mathrm{~A} 19, \\
\text { contig } \\
1\end{array}$ & $\begin{array}{l}\text { 075P11, } \\
\text { contig } \\
1\end{array}$ & $\begin{array}{l}\text { 082M07, } \\
\text { contig } 1\end{array}$ & $\begin{array}{l}\text { 057K22, } \\
\text { NLL-10 }\end{array}$ & $\begin{array}{l}042 \mathrm{~F} 24, \\
\text { contig } \\
2\end{array}$ \\
\hline $\begin{array}{l}\text { 015A19, } \\
\text { contig } 1\end{array}$ & Y & - & - & $\mathrm{N}$ & Y & $\mathrm{N}$ \\
\hline $\begin{array}{l}\text { 082M07, } \\
\text { contig } 1\end{array}$ & Y & $\mathrm{N}$ & Y & - & - & $\mathrm{N}$ \\
\hline $\begin{array}{l}\text { 133N08, } \\
\text { contig } 1\end{array}$ & - & $Y$ & Y & - & Y & $\mathrm{N}$ \\
\hline $\begin{array}{l}042 F 24, \\
\text { contig } 2\end{array}$ & $N$ & $\mathrm{~N}$ & - & $\mathrm{N}$ & - & - \\
\hline $\begin{array}{l}\text { 003B18, } \\
\text { NLL-17 }\end{array}$ & - & - & - & - & - & $Y$ \\
\hline $\begin{array}{l}\text { 136C16, } \\
\text { NLL-17 }\end{array}$ & - & - & - & - & - & $Y$ \\
\hline $\begin{array}{l}\text { 077C13, } \\
\text { NLL-10 }\end{array}$ & - & - & Y & $Y$ & - & - \\
\hline
\end{tabular}

Y: BAC-FISH signals for clones from this pair were observed in the same chromosome pair

$\mathrm{N}$ : BAC-FISH signals for clones from this pair were observed in different chromosome pairs

003B18_3) [23-25] not previously incorporated to the reference map [17] were mapped here. LanFTc1 and LanFTc2 regions differed in their estimated recombination frequencies. Between all BAC and gene-based markers from contig 1 no recombination in RILs was observed, whereas for such markers from contig 2 two recombination events were observed (see Additional file 1). 44 sequence-defined markers from linkage groups NLL-10 and 59 from NLL-17 were subjected to repeat masking and L. angustifolius genome mapping. Markers from LanFTc1 and LanFTc2 loci were not included in this alignment as there were BAC clone sequences available. High confidence alignments to genome sequences were constructed for 29 markers from the NLL-10 and 37 from NLL-17. As some redundant or closely linked molecular markers tagged the same scaffolds, the numbers of unique scaffolds anchored to particular linkage groups were lower: 28 for NLL-10 and 31 for NLL-17 (see Additional file 2). The total length of sequence assigned to the linkage map was calculated as 757164 nucleotides for NLL-10 and 1226451 for NLL-17.

\section{Assembly and functional annotation of superscaffolds carrying LanFTc genes}

$\mathrm{BES}$ markers from both BAC contigs were aligned to their respective BAC sequences as well as to the narrow-leafed lupin genome assembly. 23 BES markers from contig 1 were anchored in clone $133 \mathrm{~N} 08$ whereas one BES marker mapped to scaffold28512 (accession KB416309.1). The 5' part of 133N08 was found to overlap with the scaffold14655 (KB408211.1). 8 BESs from contig 2 were mapped to clone $137 \mathrm{O} 24$ but two remained unlinked. $5^{\prime}$ part of $137 \mathrm{O} 24$ overlapped with the scaffold72960 (AOCW01133146.1). Based on these results, superscaffolds were constructed, one for LanFTc1 encompassing 208734 nt, and the other for LanFTc2 carrying 189931 nt.

RepeatMasker and Censor annotation revealed relatively high levels of repetitive content, estimated to occupy as much as $30.2 \%$ of total sequence length in superscaffold- 1 and $35.4 \%$ in superscaffold-2. The major components of repeat fraction were retrotransposons, LTR/Gypsy and LTR/Copia. The transposon fraction was represented mainly by DNA/EnSpm. Total percentage sequence occupancy by the transposon fraction was 44-fold (superscaffold-1) and 6-fold (superscaffold-2) lower than that of retrotransposons. As BAC clones were positioned in the superscaffolds by their BAC ends,
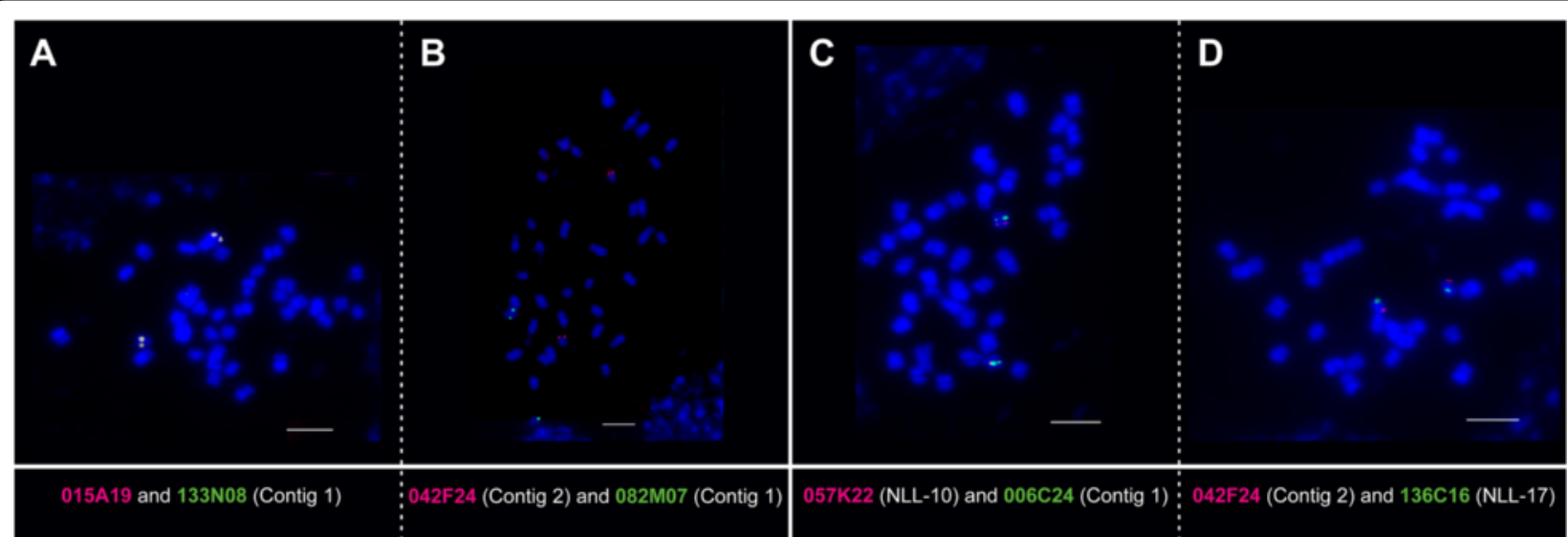

Fig. 1 Localization of BAC clones carrying LanFTC1 and LanFTC2 genes in L. angustifolius mitotic chromosomes. Chromosomes were counterstained with DAPI whereas BAC clones DNA was labelled with tetramethylrhodamine-5-dUTP - red signals and digoxigenin-11-dUPT - green signals. Common localization resulted in yellow signals. Scale bar $=5 \mu \mathrm{m}$. The following combinations of clone pairs were used in BAC-FISH: $\mathbf{a}$, both clones from contig 1 ; b, one clone from every contig; $\mathbf{c}$, a clone from contig 1 and a BAC cytogenetic marker for linkage group NLL-10; $\mathbf{d}$, a clone from contig 2 and a BAC cytogenetic marker for linkage group NLL-17 
it was possible to survey the distribution of repeats over particular clones and to compare it with type of BACFISH signals yielded by these clones on mitotic chromosomes (Table 2). No direct correlation between type of BAC-FISH signal and total repeat content nor with the presence or prevalence of different repeat families, like LTR/Copia or LTR/Gypsy, was identified. However, it should be noted that repeats were relatively abundant in these clones (from $25.21 \%$ to $49.81 \%$ ).

Hidden Markov Model gene prediction based on reference protein sequences identified four and six genes in the superscaffolds, respectively (see Additional file 3). These genes included, besides previously annotated $L a n F T c 1$ and $L a n F T c 2$, apyrase, acetyl-CoA carboxylase biotin carboxylase subunit, ethanolamine-phosphate cytidylyltransferase, galacturonokinase, and four not functionally characterized sequences (Table 3). Alignment of predicted coding sequences (CDSs) to the transcriptome assemblies of $L$. angustifolius [17], L. albus [41] and L. luteus [42] provided evidence of expression for 9, 9 and 6 genes, respectively (see Additional file 4). Based on this annotation data, gene density for LanFTc1 region was calculated as 1.9 genes/100 kbp, whereas for LanFTc2 as 3.2 genes/100 kbp. Graphical visualization of $\mathrm{BAC}, \mathrm{BES}$, linkage marker, repeat and predicted gene model localization in the superscaffolds sequences is presented at Fig. 2.

\section{Insight into micro- and macrosynteny of LanFTc regions}

Both superscaffolds with low complexity regions and repeats masked by RepeatMasker and Censor were aligned to genome sequences of nine legume species: $A$. duranensis, A. ipaensis [30], C. cajan [31], C. arietinum [32], G. max [33], L. japonicus [34], M. truncatula [35], P. vulgaris [36] and $V$. radiata [37]. Both regions revealed distinct microsyntenic patterns (see Additional files 5 and 6 where coordinates and statistics of alignments were provided). Superscaffold-1 showed links of sequence collinearity to A. duranensis chromosome 10 (region between 72.7 and $73.5 \mathrm{Mbp})$, A. ipaensis chr. 6 (113.2-114.2 Mbp), C. arietinum chr. 3 (26.3-26.5 Mbp), C. cajan scaffold 54 (0.7-1.0 Mbp), G. max chr. 16 (3.6-4.1 Mbp) and 19 (35.6-36.6 Mbp), L. japonicus chr. 1 (48.8-49.9 Mbp), M. truncatula chr. 7 (32.8-33.0 Mbp), P. vulgaris chr. 1 (20.5-22.8 Mbp), and $V$. radiata scaffold 7 (2.7-3.3 Mbp) (Fig. 3). In all these regions but $C$. cajan and L. japonicus one copy of $F T c$ gene was identified. In the $C$. cajan region showing synteny to $L a n F T c 1$ no $F T$ gene was recognized whereas in the L. japonicus syntenic region one copy of FTa gene was annotated. Superscaffold-2 was found to have higher level of synteny to genome regions of all studied species than superscaffold- 1 , however, the patterns of preserved sequence collinearity did not include the $3^{\prime}$ end of the superscaffold-2, containing the LanFTc2 gene (Fig. 4). Syntenic links observed for this scaffold matched different chromosomes than those found for superscaffold-1. Namely, they were as follows: $A$. duranensis chr. 3 (60.3$99.6 \mathrm{Mbp})$, A. ipaensis chr. 3 (70.9-85.5 Mbp), C. arietinum chr. 6 (4.1-4.4 Mbp), C. cajan chr. 5 (1.3-1.5 Mbp), G. max chr. 5 (40.2-40.3 Mbp) and chr. 8 (2.2-2.3 Mbp), L. japonicus chr. 4 (40.7-40.8 Mbp), P. vulgaris chr. 2 (46.5-46.7 Mbp), V. radiata chr. 7 (52.8-53.0 Mbp). No copy of $F T$ gene was annotated in any of these syntenic regions.

Comparative mapping of sequence defined markers from linkage groups NLL-10 and NLL-17 resulted in the identification of complex networks of syntenic links to several chromosomes in every species studied (see Additional file 7). Regions syntenic to NLL-10 included those showing microsynteny to superscaffold-1. LanFTc1

Table 2 Repetitive content (\% occupancy) of BAC clones and type of BAC-FISH signals observed on mitotic chromosomes

\begin{tabular}{|c|c|c|c|c|c|c|c|c|c|c|c|c|c|c|c|c|c|}
\hline \multirow[b]{2}{*}{$\mathrm{BAC}-\mathrm{FISH}^{\mathrm{a}}$} & \multicolumn{12}{|c|}{ Contig1 (LanFTc1) } & \multicolumn{5}{|c|}{ Contig2 (LanFTc2) } \\
\hline & $\mathrm{R}$ & $\mathrm{R}$ & $\mathrm{R}$ & $\mathrm{R}$ & $\mathrm{R}$ & $\mathrm{R}$ & $\mathrm{R}$ & S & S & S & S & S & $\mathrm{R}$ & $\mathrm{R}$ & $\mathrm{R}$ & $\mathrm{R}$ & $\mathrm{S}$ \\
\hline BAC clone & $\begin{array}{l}080 \\
\text { K01 }\end{array}$ & $\begin{array}{l}008 \\
\text { L15 }\end{array}$ & $\begin{array}{l}124 \\
\text { E17 }\end{array}$ & $\begin{array}{l}139 \\
\text { P24 }\end{array}$ & $\begin{array}{l}140 \\
\text { E06 }\end{array}$ & $\begin{array}{l}130 \\
002\end{array}$ & $\begin{array}{l}055 \\
107\end{array}$ & $\begin{array}{l}133 \\
\text { N08 } \\
\end{array}$ & $\begin{array}{l}015 \\
\text { A19 } \\
\end{array}$ & $\begin{array}{l}082 \\
\text { M07 }\end{array}$ & $\begin{array}{l}006 \\
C 24 \\
\end{array}$ & $\begin{array}{l}075 \\
\text { P11 }\end{array}$ & $\begin{array}{l}137 \\
\mathrm{O} 24\end{array}$ & $\begin{array}{l}071 \\
\text { N21 }\end{array}$ & $\begin{array}{l}100 \\
\mathrm{H} 14\end{array}$ & $\begin{array}{l}092 \\
\text { M12 }\end{array}$ & $\begin{array}{l}042 \\
F 24\end{array}$ \\
\hline DNA other & - & 0.33 & - & 0.28 & 0.39 & 0.44 & 0.39 & 0.25 & 0.34 & 0.43 & 0.41 & 0.47 & - & - & - & - & - \\
\hline DNA/EnSpm & - & - & - & - & - & - & - & 0.40 & - & - & - & - & 3.35 & - & - & - & - \\
\hline DNA/hAT & - & - & - & - & - & - & - & 0.12 & - & - & - & - & 1.54 & 0.86 & - & - & - \\
\hline DNA/IS & - & - & - & - & - & - & - & - & - & - & - & - & 0.45 & - & - & - & - \\
\hline LINE/L1 & 0.59 & 1.11 & 0.33 & 0.93 & 1.10 & 1.25 & 1.11 & 0.98 & 1.13 & 1.21 & 1.15 & 1.31 & - & - & - & - & - \\
\hline LINE/RTE & 2.99 & 1.86 & 3.61 & 1.56 & 2.17 & 1.74 & 1.55 & 1.39 & 1.88 & 2.38 & 0.42 & 0.48 & 0.31 & 0.75 & 0.84 & 1.24 & 1.30 \\
\hline LTR/Copia & 14.93 & 17.94 & 9.77 & 11.96 & 16.61 & 18.42 & 16.81 & 13.85 & 14.43 & 17.81 & 17.40 & 16.34 & 22.81 & 25.10 & 29.69 & 35.88 & 18.43 \\
\hline LTR/Gypsy & 17.10 & 14.20 & 20.66 & 16.02 & 9.16 & 10.41 & 9.27 & 12.89 & 11.67 & 10.07 & 9.59 & 4.97 & 7.59 & 15.61 & 17.53 & 11.10 & 27.26 \\
\hline Simple repeat & 0.82 & 1.26 & 0.99 & 1.26 & 1.50 & 1.52 & 1.52 & 1.34 & 1.47 & 1.47 & 1.57 & 1.63 & 1.79 & 1.98 & 1.71 & 1.59 & 2.26 \\
\hline Total repeats & 36.43 & 36.71 & 35.36 & 32.01 & 30.92 & 33.78 & 30.66 & 31.22 & 30.92 & 33.36 & 30.54 & 25.21 & 37.83 & 44.31 & 49.77 & 49.81 & 49.25 \\
\hline
\end{tabular}

${ }^{\mathrm{a}} \mathrm{R}$ - repetitive BAC-FISH signals dispersed over numerous chromosomes. S - single-locus BAC-FISH signals 
Table 3 Genes identified in superscaffolds and their transcriptomic evidence

\begin{tabular}{|c|c|c|c|c|c|c|c|}
\hline Superscaffold & Gene No. & Gene (protein) name & $\begin{array}{l}\text { CDS } \\
\text { length }\end{array}$ & $\begin{array}{l}\text { Reference } \\
\text { accession }\end{array}$ & $\begin{array}{l}\text { Fgenesh } \\
\text { + score }\end{array}$ & Positives (\%) & $\begin{array}{l}\text { Transcriptomic } \\
\text { evidence }\end{array}$ \\
\hline 1 & 1 & DNA-binding domain protein & 684 & XP_003624562.1 & 975.49 & 77.98 & ang, alb \\
\hline 1 & 2 & LanFTcl & 525 & LanFTcl & 966.60 & 100.00 & ang \\
\hline 1 & 3 & uncharacterized protein & 492 & XP_006603704.1 & 498.86 & 83.07 & ang, alb, lut \\
\hline 1 & 4 & apyrase 2-like & 1407 & XP_006598985.1 & 1916.76 & 95.51 & ang, alb, lut \\
\hline 2 & 1 & U-box domain-containing protein & 2208 & XP_006580498.1 & 2276.42 & 87.66 & alb \\
\hline 2 & 2 & acetyl-CoA carboxylase biotin carboxylase subunit & 1614 & XP_003630608.2 & 2159.24 & 91.81 & ang, alb, lut \\
\hline 2 & 3 & uncharacterized protein & 2934 & XP_006580493.1 & 2851.19 & 79.84 & ang, alb \\
\hline 2 & 4 & ethanolamine-phosphate cytidylyltransferase & 1191 & XP_006580492.1 & 1552.44 & 88.81 & ang, alb, lut \\
\hline 2 & 5 & galacturonokinase-like & 1317 & XP_006580491.1 & 1561.85 & 88.13 & ang, alb, lut \\
\hline 2 & 6 & LanFTc2 & 528 & LanFTc2 & 978.98 & 100.00 & ang, alb, lut \\
\hline
\end{tabular}

Abbreviations: ang, L. angustifolius; alb, L. albus; lut, L. luteus

gene appeared to be located in the middle of a large conserved region, marked by 9 linkage map loci spanning a distance of $15.3 \mathrm{cM}$. Despite some inversions and/or insertions/deletions, the arrays of macrosyntenic links observed in this section between sequences from $L$. angustifolius and studied species were visually similar to each other.

The most conserved arrays of collinearity between NLL-17 and sequenced genome sequences were observed for A. duranensis chr. 1, 3 and 5, A. ipaensis chr. 1, 3 and 5, C. arietinum chr. 6, 7 and 8, C. cajan chr. 6, G. $\max$ chr. 1, 5, 8 and 11, L. japonicus chr. 2 and 4, M. truncatula chr. 5 and 8, P. vulgaris chr. 2 and 3, and $V$. radiata chr. 7 and 11 . Those arrays included also all regions (but C. cajan chr. 5) matching superscaffold-2 LanFTc2 (Fig. 5). The syntenic block adjacent to LanFTc2 gene was flanked by markers 111G03_5 (53.1 cM) and 042F24_5 (73.5 cM). It should be noted that the superscaffold-2 was located at the edge of the large syntenic region $(73.0-74.1 \mathrm{cM})$, with a $L a n F T c 2$ gene itself excluded from this pattern of collinearity.

\section{Phylogenetic inference of PEBP-family sequences in sequenced legume species}

The reference set of $A$. thaliana PEBP-family protein sequences included FT (AT1G65480); TSF (NM_11815 6.1), BFT (AT5G62040), MFT (AT1G18100), and TFL1 (AT5G03840). The alignment of these sequences to the genome assemblies of 10 legume species resulted in identification of numerous homologs in the analyzed species: A. duranensis, 16; A. ipaensis, 16; C. cajan, 14; C. arietinum, 13; G. max, 22; L. japonicus 6; L. angustifolius, $15 ; M$. truncatula, 13; P. vulgaris, 11 ; and $V$. radiata, 13. Protein-based gene prediction and CDS mapping revealed that 21 sequences were putatively non-functional, truncated remnants of ancient genes and as such were excluded from further analysis. In total,
118 sequences were classified as full length homologs of legume PEBP-family genes (see Additional file 8). The Bayesian phylogenetic inference of these sequences and five $A$. thaliana references facilitated their assignment to particular subclades and evaluation of gene copy number variation. The highest number of homologs was found in G. $\max (18)$, whereas the lowest in L. japonicus (6) (Table 4). The gene copy number in the L. angustifolius (12) was close to calculated mean value for the whole group of species (11.8). The most abundant genes across analyzed taxa were from $F T a, F T b$ and TFL1 subclades, whereas the rarest were those from BFT and FTc. For some subclades, the copy number varied greatly from one species to another. It should be noted that no single copy of FTc was found in C. cajan and L. japonicus, FTb in L. angustifolius or BFT in L. japonicus.

Some PEBP-family genes were found to be clustered: 17 regions carrying at least two PEBP genes within a distance below $1 \mathrm{Mbp}$ were identified in the genomes of analyzed legume species (Table 5). One of such blocks was identified in A. duranensis and C. cajan, two in $A$. ipaensis, C. arietinum, $M$. truncatula, $P$. vulgaris and $V$. radiata, and five in G. max. The most frequent combinations of physically linked FT-family genes were $F T b$ itself or one to two FTa accompanied by one FTc. Despite the presence in numerous copies (from 2 to 5 in analyzed species), only two TFL1 homologs closely located to each other were identified. No evidence of close localization of BFT or MFT homologs was found.

The majority rule consensus tree based on the alignment of 122 PEBP-family sequences (Figs. 6, 7 and 8) shed light on evidences of numerous duplications, visualized by sister branches of shared nodes. In lineages leading to the following species or clades such duplications were observed: $C$. arietinum: two duplications of TFL1 genes, G. max: two TFL1, one BFT, FTa and FTc; $V$. radiata: one $F T b ; M$. truncatula: one $F T b ; L$. 


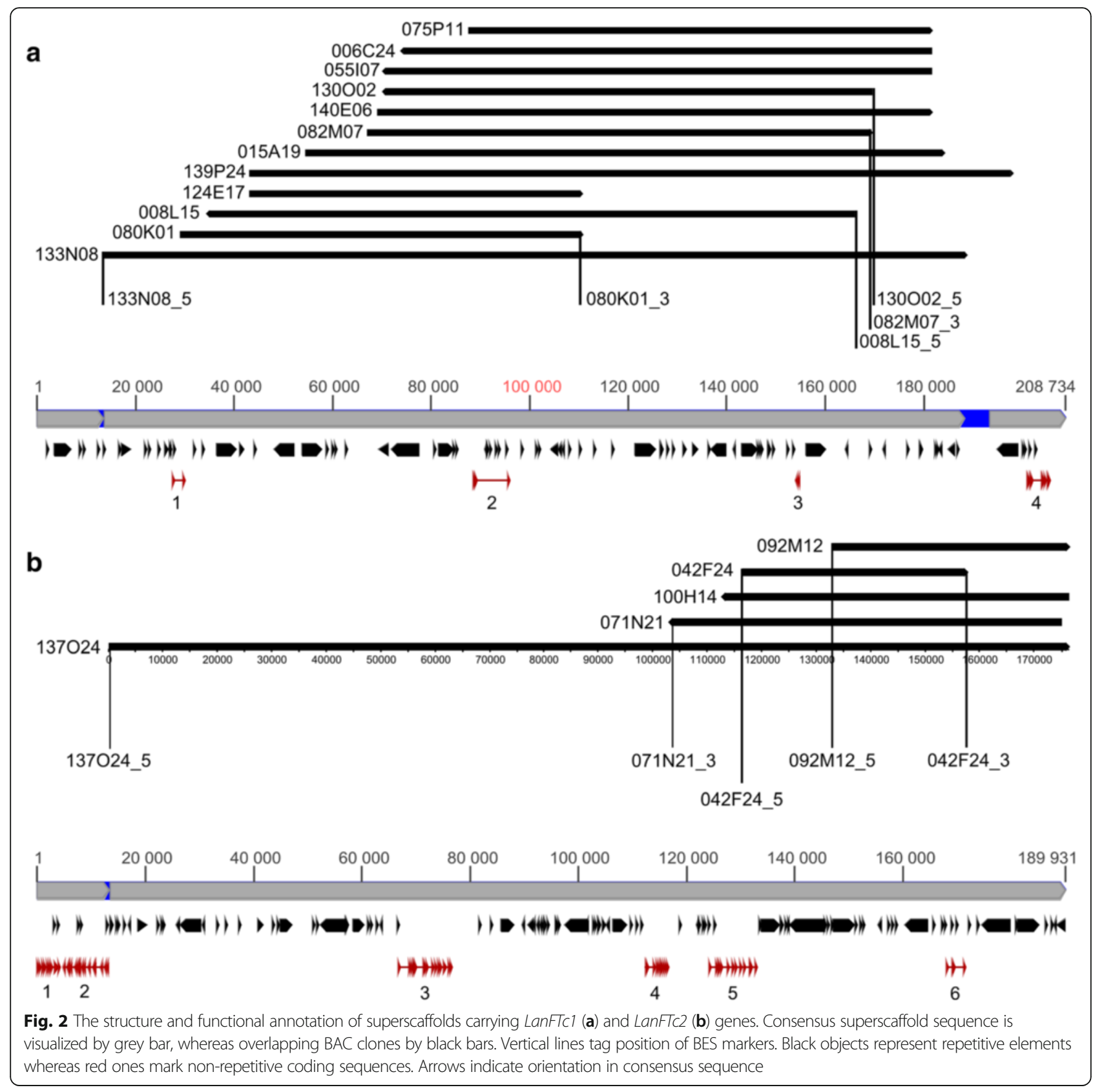

angustifolius: one FTa, FTc and MFT, and 2 TFL1, giving three closely related final copies. Duplications occurred also in genomes located at ancestral nodes linking closely related species, like the ancestor of $A$. duranensis and $A$. ipaensis: FTa, FTb, and MFT, and ancestor of C. arietinum and $M$. truncatula: FTa. The topology of the tree confirmed close relationships between sister Arachis species, between Lotus, Medicago and Cicer, as well as between Glycine, Phaseolus, Cajanus and Vigna. It also reflected directly more distant relations of early diverged Arachis and Lupinus to other succeeding clades. To facilitate further sequence analysis, gene names were assigned following the topology of the tree. As M. truncatula and G. max PEBP homologs had already common names in use [8] reference to those was provided (see Additional file 8).

\section{Promoter analysis of $F T$ homologs}

The presence of multiple copies of FT in regions with very well preserved sequence collinearity raised a question about the sequence conservation in regulatory regions of these homologs. FT upstream sequences of 8000 nt were extracted from all homologs except for L. angustifolius FTa1a and FTa1b (which are localized in short scaffolds). Annotation revealed no significant similarity to CORE1, 


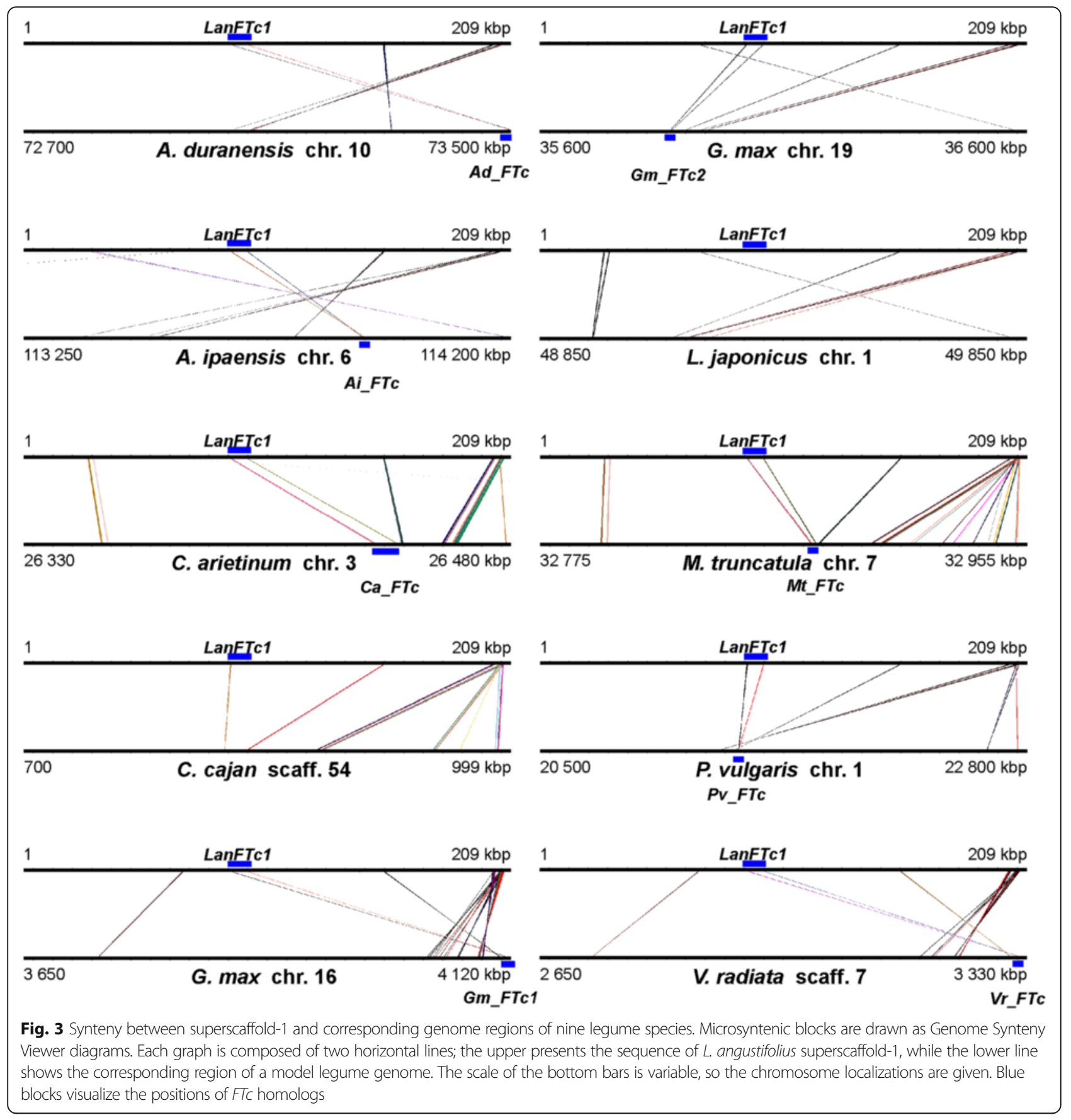

CORE2 and S4 elements. Despite numerous alignments, no evidence for conserved collinearity of P2-S3-P1 blocks was identified. Conserved positions and orientations were identified for RE-alpha and CCAAT-box sequences.

Assay of substitution rates and selective pressure of PEBP-family genes in legumes

According to the results of phylogenetic inference, PEBP sequences were grouped to six subclades, namely $B F T$, $F T a, F T b, F T c, M F T$, and TFL1. Based on the tree topology, 61 species-specific pairs of duplicated sequences were selected, including those located at sister and quasi-sister branches (i.e. paralogs) and those of the most recent common ancestor origin (i.e. orthologs). The nonsynonymous to synonymous substitution rate $(\mathrm{Ka} / \mathrm{Ks})$ ratio analysis revealed that all pairs but $C$. arietinum TFL1d/TFL1e were under strong purifying selection, with $\mathrm{Ka} / \mathrm{Ks}$ values from 0 to 0.53 (see Additional file 9). The outlier obtained for C. arietinum TFL1d/TFL1e pair may result from the incorrect assembly of $C$. arietinum TFL1e 


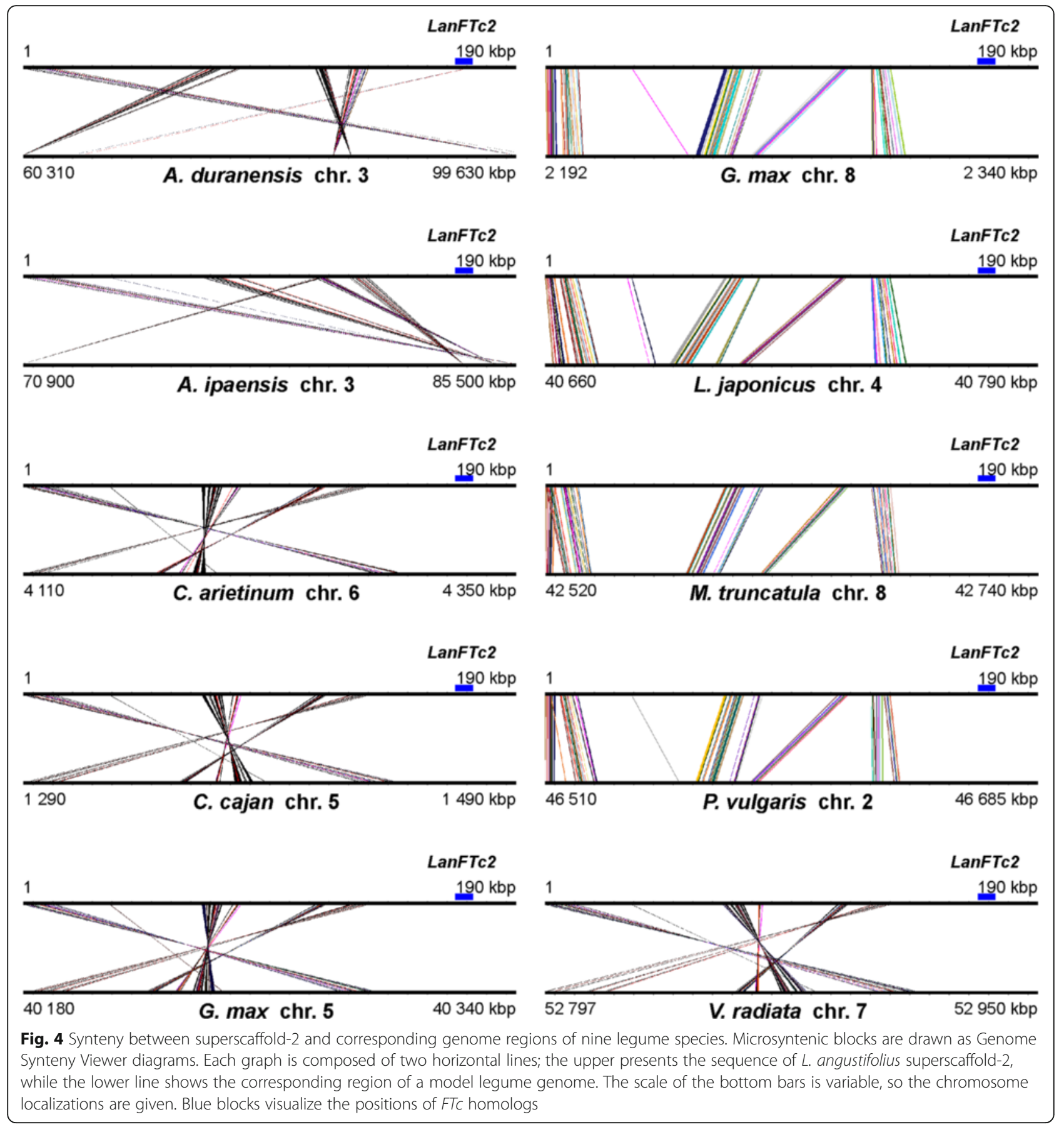

gene as this sequence was derived from three short contigs (Cascaffold1275, Cascaffold127513210 and Cascaffold127511243) and such a construct may be artificial.

The survey of subgroup-averaged hypothetical divergence time placed MFT and TFL1 as ancestral subfamilies with 157 and 117 million years ago (mya) of non-sister branch gene pair divergence time, respectively (Table 6). The expansion of non-sister branches in FTa and $F T b$ clades occurred $~ 65-76$ mya. Evolutionary history of legume species-specific paralogous PEBP copies was found to be relatively recent, as particular sister branch genes were dated from averagely 11 mya in TFL 1 to 29 mya in FTb.

\section{Discussion}

$F T$-like genes are located in regions of shared crossgenera legume synteny

The analysis based on linkage mapping, micro- and macrosynteny survey, and phylogenetic inference provided clear lines of evidence to support the hypothesis 


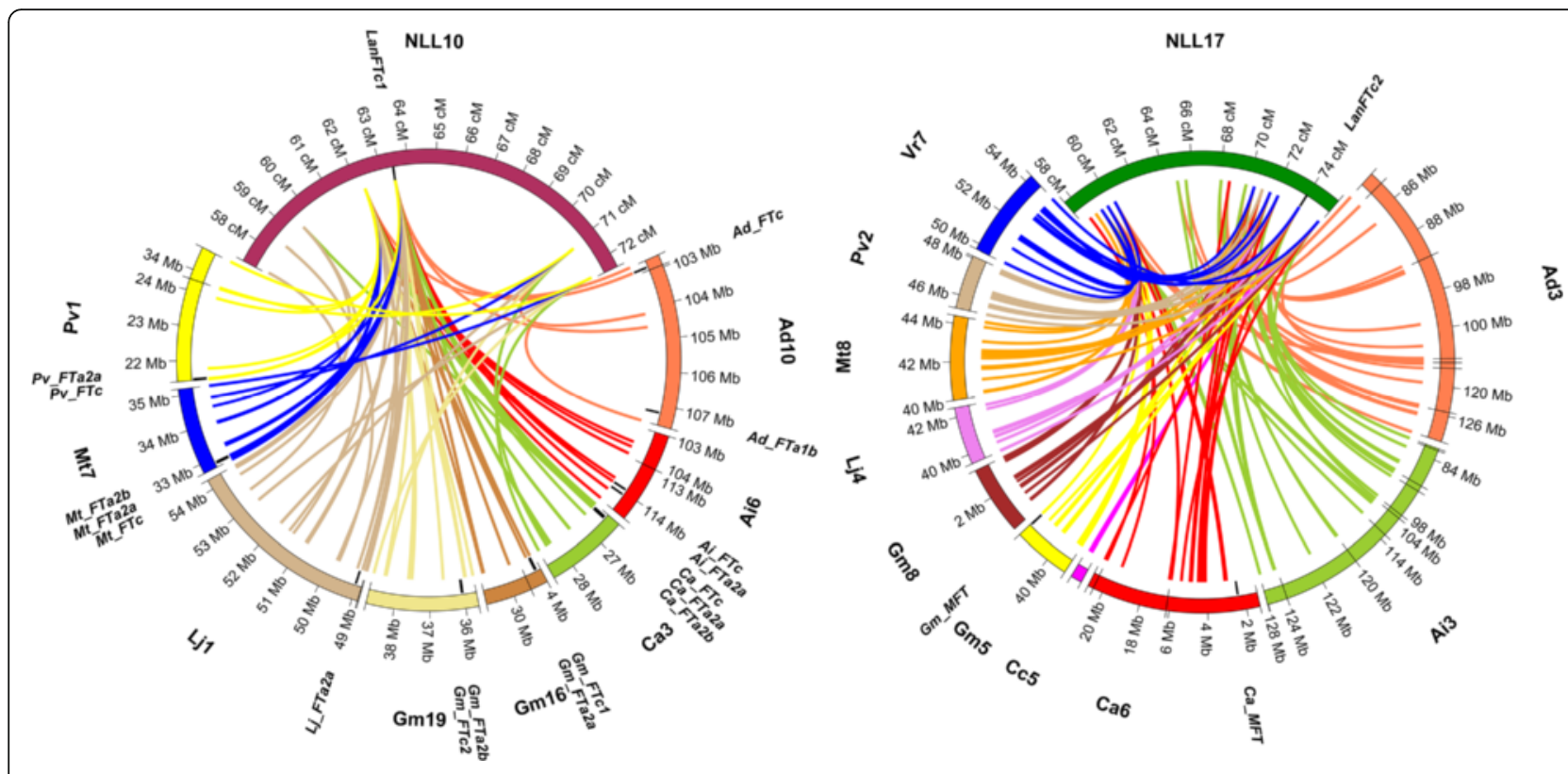

Fig. 5 Macrosyntenic links between NLL-10 and NLL-17 linkage groups and selected chromosome sequences. Circos plots show the selected regions of $L$. angustifolius linkage groups and corresponding chromosomes. Ribbons symbolize homologous links identified by DNA sequence similarity

that $L a n F T c 1$ gene, involved in vernalization pathway in Lupinus angustifolius L. [13, 18], is a direct descendant of an ancestral $F T$, whereas $L a n F T c 2$, not responsive to vernalization, is a more recent duplicate.

The availability of $L$. angustifolius draft genome sequence [29] and reference sequences of nine legume species A. ipaensis, A. duranensis [30], C. cajan [31], C. arietinum [32], G. $\max$ [33], L. japonicus [34], M. truncatula [35], P. vulgaris [36] and $V$. radiata [37] greatly contributed to lupin molecular studies [23, 24, $26,28]$. The cross-clade comparative mapping of genome sequences provided significant improvements to the phylogeny reconstruction of $F T$-like and other genes

Table 4 The number of PEBP-family genes identified in ten legume genome assemblies

\begin{tabular}{llllllll}
\hline Species & $\mathrm{FTa}$ & $\mathrm{FTb}$ & $\mathrm{FTC}$ & $\mathrm{MFT}$ & $\mathrm{TFL} 1$ & $\mathrm{BFT}$ & Total \\
\hline A. duranensis & 3 & 4 & 1 & 2 & 2 & 1 & 13 \\
A. ipaensis & 4 & 4 & 1 & 2 & 3 & 1 & 15 \\
C. cajan & 2 & 2 & 0 & 1 & 3 & 1 & 9 \\
C. arietinum & 3 & 1 & 1 & 1 & 5 & 1 & 12 \\
G. max & 4 & 4 & 2 & 1 & 5 & 2 & 18 \\
L. japonicus & 1 & 2 & 0 & 1 & 2 & 0 & 6 \\
L. angustifolius & 2 & 0 & 2 & 3 & 4 & 1 & 12 \\
M. truncatula & 3 & 2 & 1 & 1 & 3 & 1 & 11 \\
P. vulgaris & 2 & 2 & 1 & 1 & 3 & 1 & 10 \\
V. radiata & 2 & 4 & 1 & 1 & 3 & 1 & 12 \\
Total & 26 & 25 & 10 & 14 & 33 & 10 & 118 \\
\hline
\end{tabular}

from the PEBP family in legumes. Based on the model A. thaliana and the related crop species Brassica rapa it was demonstrated that synteny can be exploited to order gene models by homology providing alignment targets for mapping-by-sequencing [43]. It is a case of many species with missing full reference sequence but partial genome information available. In narrow-leafed lupin, synteny was harnessed to track the evolutionary history of duplicated chalcone isomerase like genes [26] as well as to select candidate gene family ( $F T$-like) underlying vernalization insensitivity locus $K u$, conferring early flowering phenotype [16]. The alignment of the first gene-based linkage map of $L$. angustifolius to the genome sequence of model legume $M$. truncatula revealed the existence of regions of conserved synteny in 14 lupin chromosomes [16]. The section of L. angustifolius linkage group NLL-10 containing the $K u$ locus was syntenic with a region of $M$. truncatula chromosome 7 containing three homologs of the $F T$ gene. Marker development, followed by linkage mapping of $F T$-like genes identified by Lupinus vs Medicago synteny, turned out to be a successful approach, and revealed the tight linkage of one of FTc-derived markers with locus $K u$ [18]. Moreover, a synteny survey supported the identification of affinities within $F T a, F T b$ and $F T c$ genes in $M$. truncatula and G. max genomes [8]. A synteny based approach was also used to track remnants of ancient duplications in G. $\max$ and resulted in identification which collinear relationships among blocks containing $C O$-like and FT-like genes arose after the whole-genome 
Table 5 Clusters of PEBP-family genes identified in analyzed legume species

\begin{tabular}{|c|c|c|c|}
\hline $\begin{array}{l}\text { Legume } \\
\text { chromosome }\end{array}$ & $\begin{array}{l}\text { CDS } \\
\text { positions } \\
\text { (kb) }\end{array}$ & $\begin{array}{l}\text { Spanning } \\
\text { distance } \\
\text { (kb) }\end{array}$ & $\begin{array}{l}\text { PEBP } \\
\text { homologs }\end{array}$ \\
\hline Ad04 & $123229.4-123341.6$ & 112.2 & $\begin{array}{l}\text { Ad_FTb1a, Ad_FTb1b, } \\
\text { Ad_FTb1c }\end{array}$ \\
\hline $\mathrm{AiO4}$ & $133275.2-133310.8$ & 35.7 & $\begin{array}{l}\text { Ai_FTb1a, Ai_FTb1b, } \\
\text { Ai_FTb1c }\end{array}$ \\
\hline $\mathrm{Ai06}$ & 113909.7-114074.8 & 165.2 & Ai_FTa2a, Ai_FTc \\
\hline $\mathrm{Ca} 01$ & $14759.5-14777.3$ & 17.8 & Ca_TFL1a1, Ca_TFL1a2 \\
\hline $\mathrm{CaO3}$ & 26393.9-26444.9 & 51.0 & $\begin{array}{l}\text { Ca_FTa2a, Ca_FTa2b, } \\
\text { Ca_FTc }\end{array}$ \\
\hline Cc07 & 19108.7-19335.8 & 227.1 & Cc_FTb1a, Cc_FTb2a \\
\hline Gm08 & $46616-47459.8$ & 843.8 & Gm_FTb1c, Gm_FTb2a \\
\hline Gm16 & 4135.9-4164.8 & 28.9 & Gm_FTc1, Gm_FTa2a \\
\hline Gm16 & $31110-31151.8$ & 41.8 & Gm_FTa1a, Gm_FTa1b \\
\hline Gm18 & 57653.7-57673 & 19.3 & Gm_FTb1a, Gm_FTb1b \\
\hline Gm19 & $36030.6-36051.9$ & 21.2 & Gm_FTa2b, Gm_FTc2 \\
\hline Mt07 & $774.5-817.9$ & 43.4 & Mt_FTb2a, Mt_FTb2b \\
\hline Mt07 & $32843.6-32877.1$ & 33.5 & $\begin{array}{l}\text { Mt_FTa2a, Mt_FTa2b, } \\
\text { Mt_FTc }\end{array}$ \\
\hline Pv01 & $21438.4-21457.8$ & 19.5 & Pv_FTa2a, Pv_FTc \\
\hline Pv08 & $422.5-439.3$ & 16.7 & Pv_FTb1a, Pv_FTb2a \\
\hline Vr_scaffold_7 & $3318.3-3334.5$ & 16.1 & Vr_FTa2a, Vr_FTc \\
\hline VrO4 & $20473.1-20507.3$ & 34.2 & $\begin{array}{l}\text { Vr_FTb1a, Vr_FTb1b, } \\
\text { Vr_FTb1c, Vr_FTb2a }\end{array}$ \\
\hline
\end{tabular}

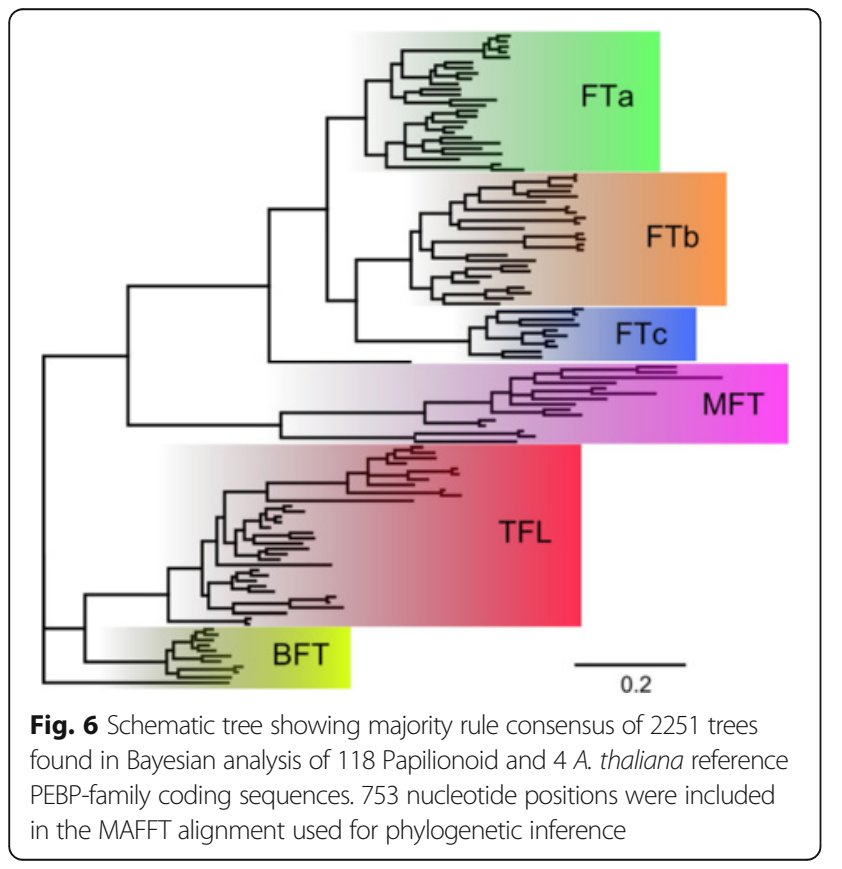

duplication (WGD) events [44]. In the present study, comparative analysis revealed that despite a complex evolution pattern of PEBP family genes, arrays of collinearity in genome regions carrying $F T$-like genes were not substantially disrupted. The survey of sequence collinearity links surrounding PEBP genes considerably supported phylogenetic inference of these genes.

\section{Copy number of PEBP-family genes in legumes}

The research revealed that a majority of PEBP-family genes are present in multiple copies in analyzed legume species. The PEBP family consists of six subclades, namely $F T a, F T b, F T c, M F T$, TFL1, and BFT. According to our knowledge, presented research is the first wholegenome survey of PEBP gene family across legume species representing several Papilionoideae lineages. It should be emphasized that the estimation of exact number of copies in particular species depends on two main constraints: the quality of the genome assembly and the availability of comprehensive reference transcriptome datasets. In the legume clade, the number of PEBP family genes has already been evaluated for $G$. max, M. truncatula, Pisum sativum and P. vulgaris genomes $[8,45,46]$. PEBP gene copy number was extensively studied in $M$. truncatula, and resulted in identification two FTa and FTb genes and one FTc, TFL1, BFT and $M F T$ gene [11, 47-49]. With the use of the new assembly of the $M$. truncatula genome we were able to identify one more $F T a$ sequence and two other copies of $T F L 1$. Four $F T a$, four $F T b$, two $F T c$, four TFL1, two BFT and two MFT sequences were identified by BLAST searches of the G. max genome [8]. Those results mostly converge with ours but we found one more TFL1 and one less MFT copies. The lacking MFT sequence, Gm08g05650, appeared only in the first genome assembly which contained also questionable $F T a \mathrm{Gm02g07650),} \mathrm{two}$ FTb (Gm08g28470, Gm18g53670) [46]. Gm02g07650, Gm08g05650, Gm18g53670 and Gm08g28470 are putatively contig-assembly artefacts of the first draft G. max genome release because all soybean PEBP gene models but those Gm02g07650, Gm08g05650, Gm18g53670 have conserved structure, and all but Gm08g28470 have duplicated counterparts generated from the last WGD [46]. Moreover, other genome-wide screening resulted in detection of all G. $\max$ copies reported here except for TFL1 (Gm13g39360) and $F T b$ (Gm08g47820), the loci removed from the new genome assembly [45]. In the present study, novel homologs were extracted from $P$. vulgaris and $M$. truncatula genome sequences, which were not identified in previous research [46], namely P. vulgaris FTb Phvul.008G003700.1 and $M$. truncatula FTa (Medtr6g033040.1 and Medtr7g085020.1), BFT (Medtr0020s0120.1), and TFL1 (Medtr1g060190.1). The molecular and in silico survey of $P$. sativum PEBP genes resulted in the deciphering of coding sequences of two FTa, 


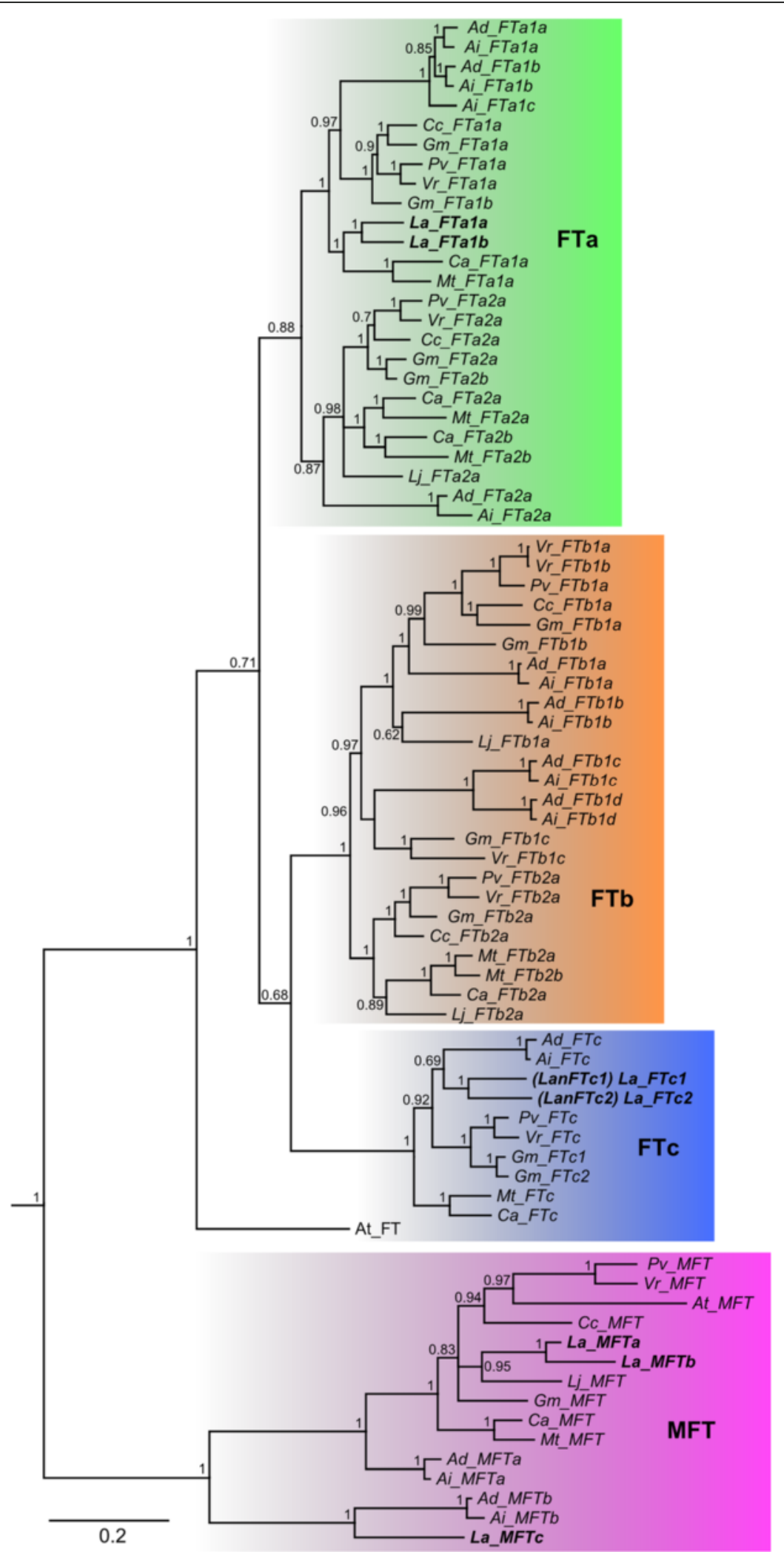

Fig. 7 Majority rule consensus of 2251 trees found in Bayesian analysis of 118 Papilionoid and 4 A. thaliana reference PEBP-family coding sequences - FT and MFT subfamilies. Numbers are posterior probabilities. 753 nucleotide positions were included in the MAFFT alignment used for phylogenetic inference 


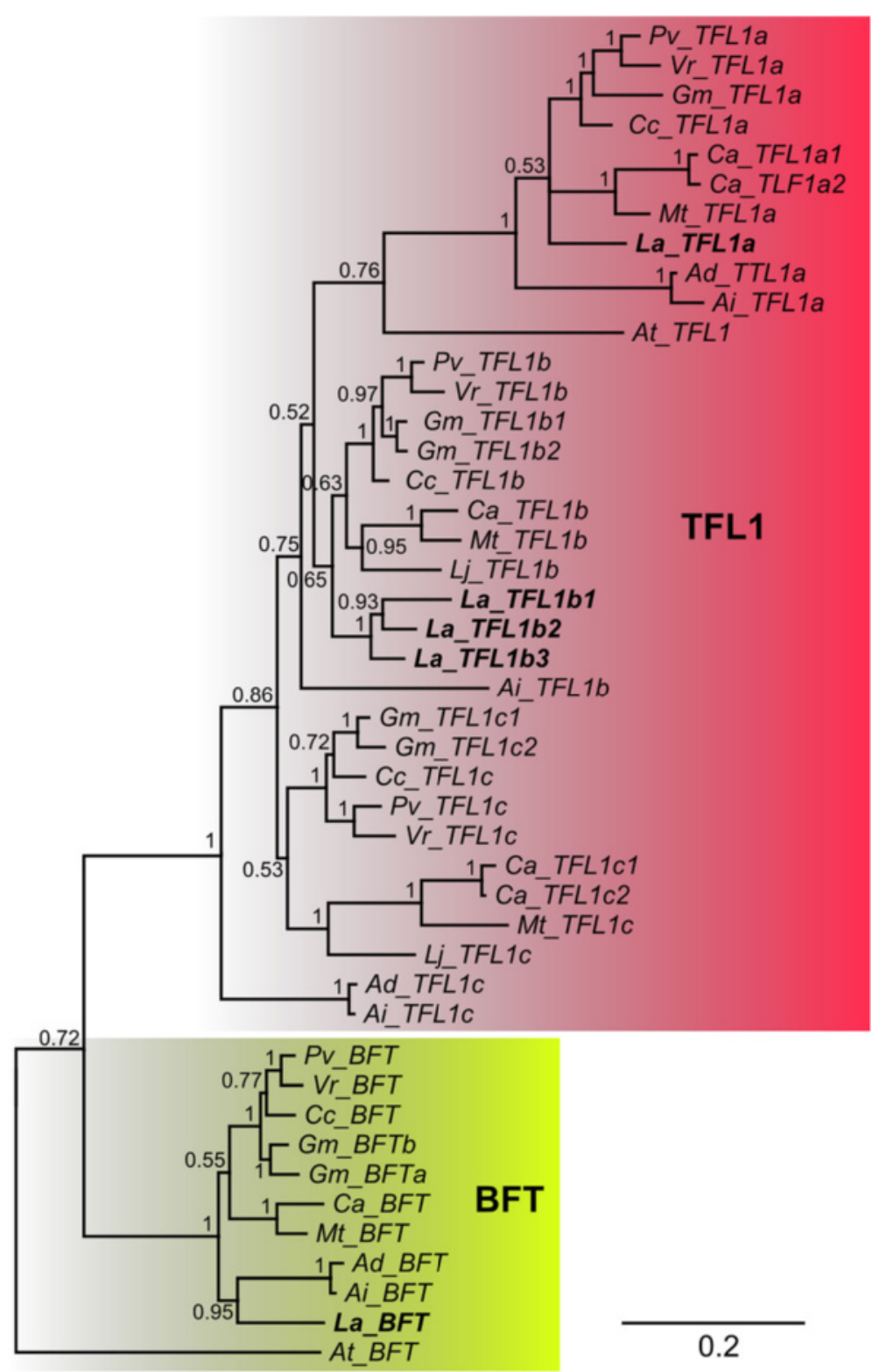

Fig. 8 Majority rule consensus of 2251 trees found in Bayesian analysis of 118 Papilionoid and 4 A. thaliana reference PEBP-family coding sequences - TFL 1 and BFT subfamilies. Numbers are posterior probabilities. 753 nucleotide positions were included in the MAFFT alignment used for phylogenetic inference

two FTb, one FTc, and three TFL1 homologs [8]. The revealed inconsistency in determination of precise number of PEBP homologs in legumes among recent reports is a minor issue which does not undermine the general conclusion that FTa, FTb and TFL1 are present in higher copy number than $F T c, M F T$ and $B F T$.

\section{Conserved motifs of FT promoter sequences}

Typically, promoters in $A$. thaliana are short with an average length of $\sim 500$ bp [50]. However, the FT promoter is much longer and contains four major blocks:
A, located from $\sim 0.4 \mathrm{~kb}$ to the first codon; B, at $\sim-2 \mathrm{~kb}$; ID, at $\sim-3.7 \mathrm{~kb}$; and $\mathrm{C}$, at $\sim-5.5 \mathrm{~kb}$. Block A contains conserved sequences: CO-responsive elements (CORE1 and CORE2) directly bound by $\mathrm{CO}$, and $\mathrm{S} 1, \mathrm{P} 1, \mathrm{~S} 3, \mathrm{P} 2$, S4 with unknown functions [51, 52]. Block B carries E-box binding site for basic-helix-loop-helix proteins promoting FT expression under blue light $[1,51]$. Block ID has no annotated element, however, it shows length variation in Arabidopsis natural populations caused by at least two independent indel events. There were some differences between these types in fitness of plants 
Table 6 Substitutions in PEBP-family paralogous comparisons and estimated divergence time

\begin{tabular}{|c|c|c|c|c|c|c|}
\hline Subfamily & Species & $\begin{array}{l}\text { No. of } \\
\text { pairs } \\
\text { analyzed }\end{array}$ & $\begin{array}{l}\text { Localization } \\
\text { on sister } \\
\text { branches }\end{array}$ & $\begin{array}{l}\text { Divergence } \\
\text { time (mya) }\end{array}$ & $\mathrm{Ka}$ & $\mathrm{Ka} / \mathrm{Ks}$ \\
\hline \multirow[t]{6}{*}{$B F T$} & $\mathrm{Gm}$ & 1 & yes & 15.9 & 0.01 & 0.08 \\
\hline & $\mathrm{Ad}$ & 1 & genus-specific & 9.1 & 0.05 & 0.53 \\
\hline & $\mathrm{Ad}$ & 1 & no & 94.5 & 0.21 & 0.21 \\
\hline & $\mathrm{Ai}$ & 3 & genus-specific & 18.1 & 0.03 & 0.16 \\
\hline & $\mathrm{Ai}$ & 1 & no & 110.8 & 0.21 & 0.18 \\
\hline & $\mathrm{Ca}$ & 2 & no & 62.4 & 0.13 & 0.20 \\
\hline \multirow[t]{11}{*}{$\mathrm{FTa}$} & Cc & 1 & no & 79.6 & 0.13 & 0.15 \\
\hline & $\mathrm{Gm}$ & 2 & no & 47.3 & 0.08 & 0.16 \\
\hline & $\mathrm{Gm}$ & 1 & yes & 11.0 & 0.03 & 0.22 \\
\hline & La & 1 & yes & 32.6 & 0.06 & 0.18 \\
\hline & Mt & 1 & no & 46.0 & 0.12 & 0.26 \\
\hline & $P \vee$ & 1 & no & 90.8 & 0.13 & 0.14 \\
\hline & $\mathrm{Vr}$ & 1 & no & 63.2 & 0.13 & 0.20 \\
\hline & $\mathrm{Ad}$ & 2 & no & 69.0 & 0.14 & 0.21 \\
\hline & $\mathrm{Ai}$ & 2 & no & 67.3 & 0.14 & 0.21 \\
\hline & $\mathrm{Cc}$ & 1 & no & 56.5 & 0.16 & 0.28 \\
\hline & $\mathrm{Gm}$ & 4 & no & 54.0 & 0.19 & 0.34 \\
\hline \multirow[t]{5}{*}{ FTb } & $\mathrm{Lj}$ & 1 & no & 56.5 & 0.18 & 0.31 \\
\hline & Mt & 1 & yes & 12.2 & 0.04 & 0.34 \\
\hline & Pv & 1 & no & 73.2 & 0.19 & 0.25 \\
\hline & $\mathrm{Vr}$ & 3 & no & 66.7 & 0.22 & 0.32 \\
\hline & $\mathrm{Vr}$ & 1 & yes & 11.2 & 0.02 & 0.14 \\
\hline \multirow[t]{3}{*}{$F T C$} & $\mathrm{Gm}$ & 1 & yes & 7.2 & 0.02 & 0.21 \\
\hline & La & 1 & yes & 41.4 & 0.11 & 0.26 \\
\hline & $\mathrm{Ad}$ & 1 & no & 139.3 & 0.37 & 0.26 \\
\hline \multirow[t]{9}{*}{ MFT } & $\mathrm{Ai}$ & 1 & no & 170.6 & 0.38 & 0.21 \\
\hline & La & 1 & no & 162.2 & 0.37 & 0.22 \\
\hline & La & 1 & yes & 28.0 & 0.09 & 0.32 \\
\hline & $\mathrm{Ad}$ & 1 & no & 87.2 & 0.20 & 0.22 \\
\hline & $\mathrm{Ai}$ & 2 & no & 114.3 & 0.24 & 0.22 \\
\hline & $\mathrm{Ca}$ & 1 & no & 81.9 & 0.16 & 0.19 \\
\hline & $\mathrm{Ca}$ & 2 & yes & 4.5 & 0.01 & 0.50 \\
\hline & Cc & 2 & no & 119.5 & 0.14 & 0.12 \\
\hline & $\mathrm{Gm}$ & 2 & no & 131.2 & 0.17 & 0.12 \\
\hline \multirow[t]{7}{*}{ TFL 1} & $\mathrm{Gm}$ & 2 & yes & 4.9 & 0.02 & 0.40 \\
\hline & La & 1 & no & 112.0 & 0.15 & 0.13 \\
\hline & La & 2 & yes & 25.0 & 0.04 & 0.17 \\
\hline & $\mathrm{Lj}$ & 1 & no & 43.0 & 0.17 & 0.38 \\
\hline & $\mathrm{Mt}$ & 2 & no & 112.4 & 0.19 & 0.16 \\
\hline & $\mathrm{PV}$ & 2 & no & 140.6 & 0.13 & 0.09 \\
\hline & $\mathrm{Vr}$ & 2 & no & 152.8 & 0.15 & 0.10 \\
\hline
\end{tabular}

grown over winter but not in flowering time [53]. Taking into consideration the position of a large indel in the LanFTc1 promoter $(\sim-2.8$ to $\sim-4.2 \mathrm{~kb})$ [13], it may correspond to Arabidopsis block ID, however, it shows lack of sequence conservation. Block $\mathrm{C}$ contains REalpha and CCAAT boxes. CCAAT box is a binding site for the NUCLEAR FACTOR Y (NFY) complex participating in making long distance DNA loop and activation of FT by bringing $\mathrm{CO}$ to CORE1 and CORE2 [52]. In general, RE-alpha and CCAAT boxes were found to be present in legume $F T$ promoters at expected positions (at $\sim-5 \mathrm{~kb}$ to $\sim-7 \mathrm{~kb}$ in legumes, $\sim-5.3 \mathrm{~kb}$ in $A$. thaliana) indicating that $F T$ promoter lengths in legumes are at least as big as in A. thaliana. It may also indicate that the NFY-mediated mechanism is preserved in legumes.

The lack of annotation of several important blocks, like CORE1 and CORE2, may relate to evolutionary sequence divergence rather than a true absence. However, it is well known that vernalization pathways evolved in temperate Cenozoic when global cooling occurred and differ between plant families which were already separated at that time [54-56]. As FT is a vernalizationresponsive gene, different regulatory elements in $F T$ promoter sequence might be present in legume clade. It was evidenced for $A$. thaliana that vernalization causes the accumulation of repressive histone modification marks at FLC locus, like $\mathrm{H} 3 \mathrm{~K} 27 \mathrm{me} 3$, silences this gene and, therefore, unlocks FT expression [57]. Differences in vernalization requirement between winter and summer $A$. thaliana accessions are conferred by allelic variation at FRIGIDA and FLC loci, causing loss or considerable reduction of function [58-60]. In $L$. angustifolius different mechanism of vernalization independence exists, based on large deletion in the promoter of $F T$, a target gene for FLC [13].

\section{Duplicated genes as traces of ancient WGD events}

In the present research, novel patterns of species-specific PEBP family gene duplications in all but L. japonicus genomes were identified, as well as remnants of preceding ancient duplications, which are thought to have occurred at ancestral nodes shared by several genera. Are these multiple copies traces of ancient WGDs or appeared independently to these events?

Episodes of WGDs have been frequent through angiosperm history [61]. It was proposed that a WGD event occurred in the common ancestor of all extant seed plants (dated 319 million years ago, mya), which was later followed by the another WGD in the common ancestor of all extant angiosperms ( 192 mya) [62]. Moreover, a phylogenomic approach harnessed to investigate the timing of gene set duplications located on syntenic gamma blocks resulted in identification of traces of old genome triplication ( 117 mya), associated with early diversification of 
the core eudicots [63]. It is anticipated that ancestral WGDs facilitated the diversification of regulatory genes important to seed and flower development and therefore ultimately contributed to major innovations which promoted the rise and eventual dominance of seed plants [64]. Taking into consideration all newly discovered and those well-documented and widely accepted genome duplications, even the relatively small genome of Arabidopsis should carry the traces of at least five WGDs [64]. However, gene pairs formed by duplication usually have a relatively short life span, as some copies may be lost, others pseudogenized, and only a limited number survive after duplication [46]. In the legume clade, an ancient WGD occurred in the progenitor line of papilionoids, the remnants of which can be seen in extant clades including the genistoids (e.g. L. angustifolius), dalbergioids (Arachis spp.), millettioids ( $P$. vulgaris, G. max, C. cajan, $V$. radiata), galegoids (M. truncatula, L. japonicus, $C$. arietinum), Xanthocercis and Cladrastis [40,65-68]. This event was dated to about 44-65 mya and directly predated the divergence of ancient lineages of Papilionoideae [32, 40, 65, 69, 70]. It should be noted that evidence was found for several independent WGDs which occurred near the base of other important legume lineages, i.e. Mimosoideae-CassiinaeCaesalpinieae, Detarieae, Cercideae and Lupinus clades, dated roughly $\sim 30-55$ mya [40]. Lupin WGD is believed to have occurred before the divergence of New World and Old World clades $[26,40]$. Some legume WGD events occurred in evolutionary recent times, like 13 mya in G. max and several mya in Arachis [33, 40]. The Ks analysis of 110 duplicated $C$. arietinum genome blocks showing synteny to four legume (M. truncatula, L. japonicus, G. max, and C. cajan) and two non-legume dicot (A. thaliana and Vitis vinifera) genomes indicated a papilionoid divergence time of 58 mya ago [32]. Galegoid and millettioid clades separated $\sim 54$ mya [70]. The survey of galegoid genome sequences using genetic distance-transversion rates at fourfold degenerate sites dated the divergence of $C$. arietinum from $L$. japonicus $\sim 20-30$ mya and from $M$. truncatula 10-20 mya [32]. Estimated dates of major WGD events converges not only with the divergence of the particular lineages but also with the appearance of new PEBP gene copies. Analysis of synonymous substitution rates in soybean genome indicated that the most of PEBP duplicated gene pairs originated from two WGD episodes, dated as 59 and 13 mya, and only few sequences appeared relatively recently, about 3-7 mya [45]. The survey of collinear relationships of homologous G. $\max$ blocks containing FT-like genes revealed that $F T a$ and $F T c$ all experienced WGDs as well as tandem duplications [44]. In general, the G. max genome has a very high number of retained duplicate genes, including terminal duplicates (visualized as sister genes in the gene trees), derived from the WGD event. Similar observations were made for Arachis and Lupinus genomes [40].

\section{Contribution of duplications to the evolution of PEBP genes}

It is anticipated that the basal clade among PEBP genes are $M F T$-like genes, which are present in angiosperms, gymnosperms, lycophytes and bryophytes [71]. The most likely scenario is that the ancestral FT/TFL1 genes originated from a duplication of an MFT-like gene after divergence of the basal plant lineage, lycophytes [46] and could have contributed to the radiation of seed plants [72]. The second duplication resulting in the production of $F T$ and TFL1 clades, encoding the proteins conferring antagonistic functions, likely occurred with the evolution of flowering plants and contributed to the development of angiosperm lineage [44, 71]. The TFL1 ancestor underwent two separate duplication episodes in the common ancestor of angiosperms, which created BFT and TFL1lineages, followed by another TFL1 duplication in the lineage leading to the Papilionoideae [46]. The pattern of $F T$-like duplications is more complex: they were at least three subsequent and two parallel duplications of FT genes during the evolution of legumes (including ancient Eurosids I specific tandem duplication) [46]. It may be summarized that all these duplications resulted in the origin of subclades $F T a, F T b$ and $F T c$ as well as in the multiplication of gene copy number in FTa and FTb clades.

In the present study numerous lineage-specific duplications of legume PEBP-family genes were revealed (Figs. 6, 7 and 8). Gene pair divergence timing based on $\mathrm{Ka} / \mathrm{Ks}$ analysis presented here (Table 6) strongly evidenced that major MFT and TFL1 lineages originated before the welldocumented WGD event around the time of the papilionoid diversification $(\sim 157$ and $\sim 117$ mya vs $\sim 48-65$ mya). The estimated date of expansion of legume-specific orthologous copies in FTa and FTb converges with the papilionoid ancestor WGD date ( $\sim 76$ and $\sim 65$ mya vs $\sim 48-65$ mya). The value of 76 mya obtained for $F T a$ resulted putatively from the existence of remnants of ancient Eurosids I specific tandem duplication in this subclade. The present study provided also novel evidence of lineage-specific WGDs, demonstrated by orchestrated convergence of averaged sister-branch gene pair duplication dates for $F T a, F T b$ and $F T c$, evaluated as 24,29 and 24 mya, respectively. Taking into consideration the total number of WGD events in the history of legumes and their ancestral lines, evolutionarily ancient MFT and BFT subclades were subjected to at least three WGDs. Such observations considerably complement the knowledge on the complex evolutionary scheme of PEBP family in legumes and validates the conclusion that the WGD events were major mechanisms launching the divergence of two large PEBP subfamilies, $F T$ and TFL1, and to a lesser extent, $B F T$ and MFT. Thus, despite so many WGD episodes, evolutionary old $M F T$ and $B F T$ subclades did not accumulate 
as many legume paralogs as $F T$ and TFL1. Indeed, the vast majority of hypothetical WGD-derived gene copies must have been completely annihilated in these subfamilies.

\section{Functional divergence of duplicated PEBP genes}

Different evolutionary patterns are possible when duplicated gene copies appear in the genome. Homologous copies of a particular gene may acquire different functions, by several possible mechanisms: pseudogenization, subfunctionalization and neo-functionalization, which can lead to the evolutionary divergence $[9,10,73]$. Indeed, functional diversification of the surviving duplicated genes is a major feature of the long-term evolution of polyploids [9]. Genes from the PEBP family, as accumulated in numerous copies in legume genomes, may be preferential targets of natural selection. Insights from patterns of molecular adaptation based on nucleotide variation among large subset of $M$. truncatula accessions from natural populations justified the conclusion that existing polymorphism of $F T$ genes in this species has probably been shaped by recent or ongoing positive selection [74]. However, our study provided well-supported evidence of strong purifying selection of PEBP genes in legumes.

Mutations are considered to play key roles in coding sequence evolution. Mutations are powerful mechanisms to facilitate the evolution of new functions as by providing the increased genetic diversity to drive the divergence of the duplicated proteins and creating discrete folding pathways contributing to the conformational diversity of newly-emerged proteins [75]. To exemplify, A. thaliana TFL1 and FT are key controllers of flowering but have opposite functions: TFL1 is a repressor, $F T$ is an activator [76]. Although these sequences are less than $60 \%$ identical, just the substitution of single amino acid (Tyr85/ Gln140 in FT and His88/Asp144 in TLF1) is sufficient to functionally convert TFL1 to FT and vice versa $[77,78]$. However, analysis of legume and other $F T$ genes revealed that although these sequences are highly conserved in rosid $F T$ genes, the legume $F T$ genes differ from the consensus at 3 to 6 positions, with $F T c$ proteins having a His rather than Gln at 140 [11]. The complete set of amino acids that drove functional divergence of all PEBP subfamilies has not yet been identified. Up to now, 46 amino acid residues that exhibited high conservation with $95 \%$ identity in the alignment encompassing $F T a, F T b, F T c, B F T$, TFL1 and MFT subclades were identified [46]. About $20 \%$ of these residues have been shown to cause loss of function when mutated [76, 79-81]. Such observations may suggest that these conserved amino acids are the prerequisites of maintaining basic functions of PEBP proteins.

\section{Conclusions}

WGD events together with tandem duplications were major mechanisms driving the divergence of two large
PEBP subfamilies, FT and TFL1, and to a lesser extent, $B F T$ and $M F T$.

Numerous lineage-specific duplications of PEBP-family genes occurred during the evolution of Papilionoideae. WGD resulted in the origin of subclades $F T a, F T b$ and $F T c$ as well as in the multiplication of gene copy number in FTa and FTb clades. Duplicated legume PEBP genes were subjected to strong purifying selection.

Two $L$. angustifolius LanFTc genes are paralogs. LanFTc1 gene, involved in vernalization pathway is a direct descendant of ancestral $F T$, whereas $L a n F T c 2$, not responsive to vernalization, appeared by subsequent duplication.

LanFTc1 gene is located in the genome region showing synteny to corresponding $F T$-like gene regions in numerous legume species, representing all main lineages of Papilionoideae. Despite a complex evolution pattern of PEBP family genes, arrays of collinearity in genome regions carrying $F T$-like genes were not substantially affected.

\section{Methods}

Chromosome localization of LanFTc genes (BAC-FISH)

DNA from clones selected from the cv. Sonet BAC library by LanFTc probe hybridization was isolated using the QIAprep Spin Miniprep Kit (Qiagen, Velno, Nederlands) and verified by PCR using insert DNA template and LanFTc1 and LanFTc2 gene-based primers [13]. Agarose gel (1\%) electrophoresis was performed for $3 \mathrm{~h}$ at $9 \mathrm{~V} / \mathrm{cm}$ to determine the quality of DNA inserts. Size marker GeneRuler ${ }^{\mathrm{m}} 1$ kb Plus (Fermentas Waltham, MA, USA) was used.

Cytological preparations of mitotic metaphase chromosomes were made from dissected root tip meristematic tissue. Chromosome squashes and the BAC-FISH procedure were performed according to the protocol [25], with few minor modifications. These changes included: probe labelling with digoxygenin-11-dUTP and tetramethyl-rhodamine-5-dUTP by incubation at $15{ }^{\circ} \mathrm{C}$ for $110 \mathrm{~min}$ followed by inactivation at $65^{\circ} \mathrm{C}$ for $15 \mathrm{~min}$ using Sensoquest Labcycler (Göttingen, Germany) and hybridization at $37^{\circ} \mathrm{C}$ for $22 \mathrm{~h}$.

\section{Linkage mapping of sequence-defined markers}

The mapping population comprised $89 \mathrm{~F}_{8}$ recombinant inbred lines (RILs) developed from the cross combination 83A:476 (domestic) $\times$ P27255 (wild-type) L. angustifolius [15]. The reference genetic map of L. angustifolius [17] containing skeleton and redundant markers was imported to MapManager v. QTXb20 [82]. Based on the segregation pattern, new markers were distributed in the existing linkage groups (map function Kosambi, linkage criterion 1e-4). MapChart software [83] was used to draw the Lupinus linkage groups. The approximate positions of attached markers were calculated by linear interpolation of adjacent markers. 


\section{Anchoring genome sequence to linkage map}

Marker sequences from linkage map groups NLL-10 and NLL-17 were used to screen the collection of $L$. angustifolius whole-genome shotgun contigs and scaffolds [29] obtained from the NCBI sequence database (Project No. PRJNA179231, assembly version GCA_000338175.1, accessions AOCW01000001-AOCW01191454). The BLAST algorithm was optimized for highly similar sequences (word size, 28; match/mismatch scores, 1/-2; and gap costs, linear). Scaffolds producing alignments with sequence identity value above $99 \%$ were integrated to the map at corresponding marker positions. Alignments with sequence identity value of $95-99 \%$ were manually checked for the possibility of sequencing or assembly errors and appropriate scaffolds were placed on map in case of positive verification.

\section{Assembly of superscaffolds carrying LanFTc genes}

BAC-end sequences (BESs) from LanFTc contigs, 24 for contig 1 and 10 for contig 2 [13], and BES-derived marker sequences were aligned to sequenced LanFTc BAC clones, 133N08 and 137O24 (accessions LN851864 and LN851865, respectively) as well as to $L$. angustifolius whole-genome shotgun assembly [29]. The BLAST (https://blast.ncbi.nlm. nih.gov/Blast.cgi) algorithm [84] was optimized for highly similar sequences (word size, 28; match/mismatch scores, $1 /-2$; and gap costs, linear). Scaffolds producing alignments with sequence identity value above $99 \%$ to particular BACs or BESs were used to assembly longer, consensus sequences of $L a n F T c 1$ and $L a n F T c 2$ regions. Based on the alignments, BESs were positioned in the constructed superscaffolds.

\section{Functional annotation of superscaffolds}

Repetitive elements were annotated and masked using RepeatMasker Web Server version 4.0.3 with implemented repeat libraries RMLib 20140131 and Dfam 1.4 (A.F.A. Smit, R. Hubley \& P. Green, unpublished data, http:// www.repeatmasker.orgo). The following options were selected: search engine, cross_match; speed/sensitivity, slow; DNA source, Arabidopsis thaliana. Preliminary masked DNA sequences were then compared to a database of transposable element encoded proteins. A third round of masking was performed using Censor maintained at Genetic Information Research Institute [85] with the following settings selected: sequence source, Viridiplantae; force translated search; mask pseudogenes. The annotation of the genetic elements was based on comparative analyses with known sequences. Integrated, non-redundant, sequences of genomic DNA, transcripts, and proteins in the RefSeq database (http://www.ncbi.nlm.nih.gov/refseq) were examined by BLAST. Moreover, scaffolds were subjected to sequence homology searches against the transcriptome sequences of L. luteus [42], L. albus [41], and L. angustifolius [17]. The following sequence repositories were used: $L$. albus, http:// comparative-legumes.org (gene index LAGI 1.0), L. luteus,
http://sra.dnanexus.com/studies/SRP014198/runs （project PRJNA170318, archive SRX159101), L. angustifolius (NCBI accession: GBRP00000000.1). CoGe BLAST algorithm [86] was used with the following parameters: e-value cut-off, 1e-10; word size, 8; gap existence cost, 5; gap elongation cost, 2; nucleotide match/mismatch scores, $1 /-2$. Sequences producing alignments with the lowest e-values were selected as references for protein-based Hidden Markov Model gene prediction in Fgenesh + [87]. Annotation data were exported to European Molecular Biology Laboratory (EMBL) feature table format and visualised in Geneious v8.1.5 [88].

\section{Micro- and macrosynteny survey}

Both superscaffold sequences, masked for repetitive contents and low-complexity regions, were aligned to the following genome sequences: A. duranensis (accession V14167) and A. ipaensis (accession K30076) (Peanut Genome Project), C. cajan [31] (project PRJNA72815, v1.0), C. arietinum [32] (v1.0 unmasked, http://comparative-legumes.org), G. $\max$ [33] (Phytozome v9.0 unmasked, http:// www.phytozome.net), L. japonicus [34] (pseudomolecules v2.5 unmasked, http://www.kazusa.or.jp), M. truncatula [35] (strain A17, JCVI v4.0 unmasked, http://www.jcvi.org/ medicago/), P. vulgaris [36] (v1.0, https://phytozome.jgi. doe.gov/pz/portal.html), and $V$. radiata [37] (project PRJNA243847). The CoGe BLAST algorithm [86] was used to make sequence similarity analyses with the following parameters: e-value cut-off, 1e-10; word size, 8; gap existence cost, 5; gap elongation cost, 2; nucleotide match/mismatch scores, $1 /-2$. Sequences producing alignments to numerous loci dispersed over many chromosomes were marked as repetitive and excluded from further analysis. Sequence collinearity blocks were visualized using the Web-based Genome Synteny Viewer [89] and Circos [90].

All marker sequences from linkage groups NLL-10 and NLL-17 [17, 23, 24] were repeat-masked by RepeatMasker and Censor [85]. Masked sequences were then aligned to the $L$. angustifolius whole-genome shotgun assembly [29] using BLAST algorithm optimized for highly similar sequences. Alignments with sequence identity value below $95 \%$ were discarded, whereas alignments with sequence identity value equal or above $95 \%$ were manually checked for the distribution of mismatches, and if accepted, appropriate markers were replaced by scaffolds. Obtained set of markers and scaffolds with assigned genetic distance positions was subjected to RepeatMasker and Censor [85] masking, followed by CoGe BLAST [86] mapping to sequences of nine sequenced legumes (as described).

\section{Identification of PEBP-family homologs in sequenced leg- ume genomes}

Selected $A$. thaliana reference sequences (FT (AT1G6 5480); TWIN SISTER OF FT, TSF (NM_118156.1), 
BROTHER OF FT, BFT (AT5G62040), MOTHER OF FT, MFT (AT1G18100), and TERMINAL FLOWER 1, TFL1 (AT5G03840) were aligned to the G. max genome sequence by custom BLAST implemented in Geneious [88] under the following parameters: e-value cut-off, 1e-6; word size, 7; gap existence cost, 5; gap elongation cost, 2; nucleotide match/mismatch scores, 2/-3. Genome sequence regions, extended by $10000 \mathrm{nt}$ in both directions from alignment locus, were extracted and submitted to Fgenesh + [87] gene prediction using original $A$. thaliana protein sequences as references. Coding (CDS) and protein sequences obtained from Fgenesh + were compared with those deposited in Phytozome G. $\max$ annotated genome assembly at appropriate nucleotide positions (https://phytozome.jgi.doe.gov/pz/ portal.html). To facilitate further tracking of these sequences, Phytozome accession numbers were added to sequence names. The set of G. $\max$ PEBP-family protein sequences was subsequently used to screen the genome assemblies of $L$. angustifolius [29] and eight other legume species using the same settings as those applied for G. max. The transcriptome unigene assembly of $L$. angustifolius was also searched [17]. Fgenesh + gene predictions were made using G. $\max$ protein sequences as references. Predicted PEBP-family protein sequences were compared with annotation data deposited at PeanutBase http://www.peanutbase.org (A. duranensis and A. ipaensis) and LegumeIP database [91] (C. cajan, $C$. arietinum, $L$. japonicus, $M$. truncatula, $P$. vulgaris). Accession numbers from these databases were assigned to predicted sequences if applicable.

\section{Phylogenetic inference of PEBP-family sequences}

The set of 122 PEBP-family protein coding sequences, including 4 reference $A$. thaliana sequences, was selected (see Additional file 10). Multiple translation sequence alignment was achieved in MAFFT v7.017 [92], using the following parameters: standard genetic code, BLOSUM 62 substitution matrix, gap open penalty 1.25. Two algorithms were tested, G-INS optimized for global homology, and E-INS for multiple conserved domains and long gaps. Bayesian inference of phylogeny was performed in MrBayes 3.2.2 [93]. A phylogenetic tree was drawn in Geneious [88] using specified parameters and settings (see Additional file 11). Based on the topology of the tree, paralogous and orthologous pairs of sequences were selected. Pairwise translation sequence alignments were done in MAFFT v7.017, using E-INS, BLOSUM 80 and gap open penalty 1.25 . Selection pressure parameters, Ka (the number of nonsynonymous substitutions per nonsynonymous site), Ks (the number of synonymous substitutions per synonymous site), and $\mathrm{Ka} / \mathrm{Ks}$ ratios were calculated in DnaSP 5 [94]. The estimation of dates of duplication events was based on the Ks parameter [45].
Table 7 Conserved motifs used for FT promoter screening

\begin{tabular}{ll}
\hline Motif & Sequence \\
\hline CCAAT-box & ATTGGA \\
CORE2 & GATTGTGGTATGATTT \\
E-box & ACAAGTGG \\
I-box & TTATCAA \\
P1 & ACCACA \\
P2 & GTGTGGT \\
RE-alpha & TTGGTTG \\
S1 & TAGAT \\
S2_CORE1 & CAATGTGTGATGTACGTAG \\
S3 & TTGGAA \\
S4 & ATAATTTGAATATT \\
TATA_box & TATAA \\
\hline
\end{tabular}

\section{Identification of conserved motifs in FT promoter sequences}

Upstream regions counting $8000 \mathrm{nt}$ from the first triplet of $F T$ homolog CDS sequence were extracted from the genome assemblies. Selection of reference motifs was based on recently published data [51] (Table 7). Annotation was done in Geneious [88] using $100 \%$ nucleotide identity threshold for short motifs (up to $8 \mathrm{nt}$ in length) and minimum length of $13 \mathrm{nt}$ for longer motifs.

\section{Additional files}

Additional file 1: Segregation data for markers in L. angustifolius linkage groups NLL-10 and NLL-17. (XLS $132 \mathrm{~kb}$ )

Additional file 2: Centimorgan positions and alignment statistics for $L$. angustifolius genome scaffolds anchored to the updated reference linkage map (groups NLL-10 and NLL-17). (XLS 49 kb)

Additional file 3: Reference accessions assigned to genes predicted in superscaffolds carrying LanFTc1 and LanFTc2 genes. (XLS 34 kb)

Additional file 4: Transcriptome sequences assigned to genes predicted in superscaffolds carrying LanFTc1 and LanFTc2 genes. (XLS 48 kb)

Additional file 5: Microsyntenic links identified between superscaffold-1 and legume genome regions. Sequences producing numerous links dispersed over many chromosomes were denoted as "repetitive". (XLS 837 kb)

Additional file 6: Microsyntenic links identified between superscaffold-2 and legume genome regions. Sequences producing numerous links dispersed over many chromosomes were denoted as "repetitive". (XLS 259 kb)

Additional file 7: Sequence homology links identified between linkage groups NLL-10 and NLL-17 and legume genomes. (DOC 3709 kb)

Additional file 8: PEBP-family reference sequences and homologs identified in the genomes of ten legume species. (XLS $74 \mathrm{~kb}$ )

Additional file 9: Substitution rates, selective pressure and estimated divergence time of PEBP-family genes in legumes. (XLS 56 kb)

Additional file 10: The set of 123 PEBP-family protein coding sequences used for phylogenetic inference. (DOC $95 \mathrm{~kb}$ )

Additional file 11: Settings applied to perform MrBayes inference of phylogeny. (DOC $31 \mathrm{~kb}$ ) 


\section{Abbreviations}

Ad: Arachis duranensis; Ai: Arachis ipaensis; BAC: Bacterial artificial chromosome; BES: BAC-end sequence; BFT: Brother of FT and TFL1; Ca: Cicer arietinum; Cc: Cajanus cajan; CDS: Coding sequence; FISH: Fluorescent in situ hybridization; FLC: Flowering locus C; FT: Flowering locus T; Gm: Glycine max; La: Lupinus angustifolius; LanFTc1: Lupinus angustifolius FTC1; LanFTC2: Lupinus angustifolius FTC2; Lj: Lotus japonicus; MFT: Mother of FT and TFL1; Mt: Medicago truncatula; NLL: Narrow-leafed lupin linkage group; PEBP: Phosphatidylethanolamine binding protein; Pv: Phaseolus vulgaris; TFL1: Terminal flower 1; TSF: Twin sister of FT; Vr: Vigna radiata

\section{Acknowledgements}

We would like to thank Dr Hua'an Yang (Department of Agriculture and Food Western Australia, Perth, Australia) for the seeds of the L. angustifolius mapping population.

\section{Funding}

The study was realized with the financial support of the Polish Ministry of Agriculture and Rural Development (Biological Progress in Plant Production grant). Funding body had no role in study design, data analysis, result interpretation and manuscript writing.

\section{Availability of data and materials}

Mapping data, predicted gene sequences and alignment data are presented as additional files. L. angustifolius BAC library is available in the Institute of Plant Genetics of the Polish Academy of Sciences in Poznań (Poland). Phylogenetic data were deposited in TreeBASE and can be accessed using the following URL: http://purl.org/phylo/treebase/phylows/study/ TB2:S19812?format=html.

\section{Authors' contributions}

MK carried out sequence annotation, synteny analysis, phylogenetic inference, drafted a manuscript and prepared all figures but one. SR participated in identification of PEBP sequence homologs in analyzed species and assignment of scaffolds to linkage groups. KW performed BAC-FISH analysis and prepared Fig. 1. MK, MN, BW and BN had a contribution in the general concept of the research scheme and participated in manuscript drafting. All authors read and approved the final manuscript.

\section{Competing interests}

The authors declare that the research was conducted in the absence of any financial and non-financial relationships that could be construed as a potential conflict of interest.

\section{Consent for publication}

Not applicable.

\section{Ethics approval and consent to participate}

Not applicable.

\section{Author details}

${ }^{1}$ Institute of Plant Genetics of the Polish Academy of Sciences, Strzeszyńska 34, 60-479 Poznań, Poland. ${ }^{2}$ Natural Capital and Plant Health, Royal Botanic Gardens Kew, Wakehurst Place, Ardingly, West Sussex RH17 6TN, UK. ${ }^{3}$ School of Plant Biology, The University of Western Australia, 35 Stirling Highway, Crawley, WA 6009, Australia. ${ }^{4}$ The UWA Institute of Agriculture, The University of Western Australia, 35 Stirling Highway, Crawley, WA 6009, Australia.

\section{Received: 7 June 2016 Accepted: 8 October 2016}

\section{Published online: 21 October 2016}

\section{References}

1. Liu L, Adrian J, Pankin A, Hu J, Dong X, von Korff M, Turck F. Induced and natural variation of promoter length modulates the photoperiodic response of FLOWERING LOCUS T. Nat Commun. 2014;5:4558.

2. Hengst U, Albrecht H, Hess D, Monard D. The phosphatidylethanolaminebinding protein is the prototype of a novel family of serine protease inhibitors. J Biol Chem. 2001;276(1):535-40.

3. Banfield MJ, Barker JJ, Perry AC, Brady RL. Function from structure? The crystal structure of human phosphatidylethanolamine-binding protein suggests a role in membrane signal transduction. Structure. 1998;6(10):1245-54.
4. Danilevskaya ON, Meng X, Hou Z, Ananiev EV, Simmons CR. A genomic and expression compendium of the expanded PEBP gene family from maize. Plant Physiol. 2008;146(1):250-64.

5. Turck F, Fornara F, Coupland G. Regulation and identity of florigen: FLOWERING LOCUS T moves center stage. Annu Rev Plant Biol. 2008;59:573-94.

6. Andres F, Coupland $G$. The genetic basis of flowering responses to seasonal cues. Nat Rev Genet. 2012;13(9):627-39.

7. Michaels SD, Himelblau E, Kim SY, Schomburg FM, Amasino RM. Integration of flowering signals in winter-annual Arabidopsis. Plant Physiol. 2005;137(1):149-56.

8. Hecht V, Laurie RE, Vander Schoor JK, Ridge S, Knowles CL, Liew LC, Sussmilch FC, Murfet IC, Macknight RC, Weller JL. The pea GIGAS gene is a FLOWERING LOCUS T homolog necessary for graft-transmissible specification of flowering but not for responsiveness to photoperiod. Plant Cell. 2011;23(1):147-61.

9. Blanc $\mathrm{G}$, Wolfe KH. Functional divergence of duplicated genes formed by polyploidy during Arabidopsis evolution. Plant Cell. 2004;16:1679-91.

10. Cusack BP, Wolfe KH. When gene marriages don't work out: divorce by subfunctionalization. Trends Genet. 2007:23:270-2.

11. Laurie RE, Diwadkar P, Jaudal M, Zhang L, Hecht V, Wen J, Tadege M, Mysore KS, Putterill J, Weller JL, et al. The Medicago FLOWERING LOCUS T homolog, MtFTa1, is a key regulator of flowering time. Plant Physiol. 2011;156(4):2207-24.

12. Kong F, Liu B, Xia Z, Sato S, Kim BM, Watanabe S, Yamada T, Tabata S, Kanazawa A, Harada K, et al. Two coordinately regulated homologs of FLOWERING LOCUS T are involved in the control of photoperiodic flowering in soybean. Plant Physiol. 2010;154(3):1220-31.

13. Nelson MN, Książkiewicz M, Rychel S, Besharat N, Taylor CM, Wyrwa K, Jost R, Erskine W, Cowling WA, Berger JD, et al. The loss of vernalisation requirement in narrow-leafed lupin is associated with a deletion in the promoter and de-repressed expression of an FT homologue. New Phytol. 2016. doi:10.1111/nph.14094.

14. Naganowska B, Wolko B, Sliwińska E, Kaczmarek Z. Nuclear DNA content variation and species relationships in the genus Lupinus (Fabaceae). Ann Bot. 2003;92:349-55.

15. Boersma JG, Pallotta M, Li C, Buirchell BJ, Sivasithamparam K, Yang H. Construction of a genetic linkage map using MFLP and identification of molecular markers linked to domestication genes in narrow-leafed lupin (Lupinus angustifolius L.). Cell Mol Biol Lett. 2005;10:331-44.

16. Nelson MN, Phan HTT, Ellwood SR, Moolhuijzen PM, Hane J, Williams A, O'Lone CE, Fosu-Nyarko J, Scobie M, Cakir M, et al. The first gene-based map of Lupinus angustifolius L.-location of domestication genes and conserved synteny with Medicago truncatula. Theor Appl Genet. 2006;113:225-38.

17. Kamphuis LG, Hane JK, Nelson MN, Gao L, Atkins CA, Singh KB. Transcriptome sequencing of different narrow-leafed lupin tissue types provides a comprehensive uni-gene assembly and extensive gene-based molecular markers. Plant Biotechnol J. 2015;13:14-25.

18. Kroc M, Koczyk G, Święcicki W, Kilian A, Nelson MN. New evidence of ancestral polyploidy in the Genistoid legume Lupinus angustifolius L. (narrow-leafed lupin). Theor Appl Genet. 2014;127:1237-49.

19. Nelson MN, Moolhuijzen PM, Boersma JG, Chudy M, Lesniewska K, Bellgard M, Oliver RP, Swiecicki W, Wolko B, Cowling WA, et al. Aligning a new reference genetic map of Lupinus angustifolius with the genome sequence of the model legume, Lotus japonicus. DNA Res. 2010;17:73-83.

20. Kasprzak A, Safár J, Janda J, Dolezel J, Wolko B, Naganowska B. The bacterial artificial chromosome (BAC) library of the narrow-leafed lupin (Lupinus angustifolius L.). Cell Mol Biol Lett. 2006;11:396-407.

21. Gao L-L, Hane JK, Kamphuis LG, Foley R, Shi B-J, Atkins CA, Singh KB. Development of genomic resources for the narrow-leafed lupin (Lupinus angustifolius): construction of a bacterial artificial chromosome (BAC) library and BAC-end sequencing. BMC Genomics. 2011;12:521.

22. Kaczmarek A, Naganowska B, Wolko B. Karyotyping of the narrow-leafed lupin (Lupinus angustifolius L.) by using FISH, PRINS and computer measurements of chromosomes. J Appl Genet. 2009;50:77-82.

23. Książkiewicz M, Wyrwa K, Szczepaniak A, Rychel S, Majcherkiewicz K, Przysiecka Ł, Karlowski W, Wolko B, Naganowska B. Comparative genomics of Lupinus angustifolius gene-rich regions: BAC library exploration, genetic mapping and cytogenetics. BMC Genomics. 2013;14:79.

24. Książkiewicz M, Zielezinski A, Wyrwa K, Szczepaniak A, Rychel S, Karlowski W, Wolko B, Naganowska B. Remnants of the legume ancestral genome preserved in gene-rich regions: insights from Lupinus angustifolius physical, genetic, and comparative mapping. Plant Mol Biol Rep. 2015;33:84-101. 
25. Lesniewska K, Ksiazkiewicz M, Nelson MN, Mahé F, Aïnouche A, Wolko B, Naganowska B. Assignment of 3 genetic linkage groups to 3 chromosomes of narrow-leafed lupin. J Hered. 2011;102:228-36.

26. Przysiecka L, Książkiewicz M, Wolko B, Naganowska B. Structure, expression profile and phylogenetic inference of chalcone isomerase-like genes from the narrowleafed lupin (Lupinus angustifolius L.) genome. Front Plant Sci. 2015;6:268.

27. Wyrwa K, Ksiazkiewicz M, Szczepaniak A, Susek K, Podkowinski J, Naganowska B. Integration of Lupinus angustifolius L. (narrow-leafed lupin) genome maps and comparative mapping within legumes. Chromosome Res. 2016:24:355-378.

28. Zielezinski A, Potarzycki P, Książkiewicz M, Karłowski W. Annotating a nonmodel plant genome - a study on the narrow-leafed lupin. Biotechnologia. 2012;93:318-32.

29. Yang H, Tao Y, Zheng Z, Zhang Q, Zhou G, Sweetingham MW, Howieson JG, Li C. Draft genome sequence, and a sequence-defined genetic linkage map of the legume crop species Lupinus angustifolius L. PLoS One. 2013;8:e64799.

30. Bertioli DJ, Cannon SB, Froenicke L, Huang G, Farmer AD, Cannon EKS, Liu X, Gao D, Clevenger J, Dash S, et al. The genome sequences of Arachis duranensis and Arachis ipaensis, the diploid ancestors of cultivated peanut. Nat Genet. 2016;48(4):438-46.

31. Varshney RK, Chen W, Li Y, Bharti AK, Saxena RK, Schlueter JA, Donoghue MTA, Azam S, Fan G, Whaley AM, et al. Draft genome sequence of pigeonpea (Cajanus cajan), an orphan legume crop of resource-poor farmers. Nat Biotechnol. 2012;30:83-9.

32. Varshney RK, Song C, Saxena RK, Azam S, Yu S, Sharpe AG, Cannon S, Baek J, Rosen BD, Tar'an B, et al. Draft genome sequence of chickpea (Cicer arietinum) provides a resource for trait improvement. Nat Biotechnol. 2013;31:240-6.

33. Schmutz J, Cannon SB, Schlueter J, Ma J, Mitros T, Nelson W, Hyten DL, Song Q, Thelen JJ, Cheng J, et al. Genome sequence of the palaeopolyploid soybean. Nature. 2010;463:178-83.

34. Sato S, Nakamura Y, Kaneko T, Asamizu E, Kato T, Nakao M, Sasamoto S, Watanabe A, Ono A, Kawashima K, et al. Genome structure of the legume, Lotus japonicus. DNA Res. 2008;15:227-39.

35. Young ND, Debellé F, Oldroyd GED, Geurts R, Cannon SB, Udvardi MK, Benedito VA, Mayer KFX, Gouzy J, Schoof H, et al. The Medicago genome provides insight into the evolution of rhizobial symbioses. Nature. 2011;480:520-4.

36. Schmutz J, McClean PE, Mamidi S, Wu GA, Cannon SB, Grimwood J, Jenkins J, Shu S, Song Q, Chavarro C, et al. A reference genome for common bean and genome-wide analysis of dual domestications. Nat Genet. 2014;46:707-13.

37. Kang YJ, Kim SK, Kim MY, Lestari P, Kim KH, Ha B-K, Jun TH, Hwang WJ, Lee $T$, Lee J, et al. Genome sequence of mungbean and insights into evolution within Vigna species. Nat Commun. 2014,5:5443.

38. Gladstones J, Hill G. Selection for economic characters in Lupinus angustifolius and L. digitatus. 2. Time of flowering. Aust J Exp Agric. 1969;9(37):213-20.

39. Boersma JG, Buirchell BJ, Sivasithamparam K, Yang H. Development of a sequence-specific PCR marker linked to the Ku gene which removes the vernalization requirement in narrow-leafed lupin. Plant Breeding. 2007;126:306-9.

40. Cannon SB, McKain MR, Harkess A, Nelson MN, Dash S, Deyholos MK, Peng $Y$, Joyce $B$, Stewart CN, Rolf M, et al. Multiple polyploidy events in the early radiation of nodulating and nonnodulating legumes. Mol Biol Evol. 2015;32:193-210.

41. O'Rourke JA, Yang SS, Miller SS, Bucciarelli B, Liu J, Rydeen A, Bozsoki Z, Uhde-Stone C, Tu ZJ, Allan D, et al. An RNA-Seq transcriptome analysis of orthophosphate-deficient white lupin reveals novel insights into phosphorus acclimation in plants. Plant Physiol. 2013;161:705-24.

42. Parra-González LB, Aravena-Abarzúa GA, Navarro-Navarro CS, Udall J, Maughan J, Peterson LM, Salvo-Garrido HE, Maureira-Butler IJ. Yellow lupin (Lupinus luteus L.) transcriptome sequencing: molecular marker development and comparative studies. BMC Genomics. 2012;13:425.

43. Galvao VC, Nordstrom K, Lanz C, Sulz P, Mathieu J, Pose D, Schmid M, Weigel D, Schneeberger K. Synteny-based mapping-by-sequencing enabled by targeted enrichment. Plant J. 2012;71(3):517-26.

44. Fan C, Hu R, Zhang X, Wang X, Zhang W, Zhang Q, Ma J, Fu YF. Conserved CO-FT regulons contribute to the photoperiod flowering control in soybean. BMC Plant Biol. 2014;14:9.

45. Zhang LF, Xu R, Zhang YW, Dai HY, Wang CJ, Li W, Zhang J. Preliminary analysis of the PEBP gene family in soybean (Glycine max). J Plant Genet Res. 2015;16(1):151-7.

46. Wang Z, Zhou Z, Liu Y, Liu T, Li Q, Ji Y, Li C, Fang C, Wang M, Wu M, et al. Functional evolution of phosphatidylethanolamine binding proteins in soybean and Arabidopsis. Plant Cell. 2015;27(2):323-36.
47. Hecht V, Foucher F, Ferrandiz C, Macknight R, Navarro C, Morin J, Vardy ME, Ellis N, Beltran JP, Rameau C, et al. Conservation of Arabidopsis flowering genes in model legumes. Plant Physiol. 2005;137(4):1420-34.

48. Liew LC, Hecht V, Laurie RE, Knowles CL, Vander Schoor JK, Macknight RC, Weller JL. DIE NEUTRALIS and LATE BLOOMER 1 contribute to regulation of the pea circadian clock. Plant Cell. 2009;21(10):3198-211.

49. Yeoh CC, Balcerowicz M, Laurie R, Macknight R, Putterill J. Developing a method for customized induction of flowering. BMC Biotechnol. 2011;11:36.

50. Korkuc P, Schippers JH, Walther D. Characterization and identification of cisregulatory elements in Arabidopsis based on single-nucleotide polymorphism information. Plant Physiol. 2014;164(1):181-200.

51. Adrian J, Farrona S, Reimer JJ, Albani MC, Coupland G, Turck F. cisRegulatory elements and chromatin state coordinately control temporal and spatial expression of FLOWERING LOCUS T in Arabidopsis. Plant Cell. 2010;22(5):1425-40.

52. Cao S, Kumimoto RW, Gnesutta N, Calogero AM, Mantovani R, Holt 3rd BF. A distal CCAAT/NUCLEAR FACTOR Y complex promotes chromatin looping at the FLOWERING LOCUS T promoter and regulates the timing of flowering in Arabidopsis. Plant Cell. 2014;26(3):1009-17.

53. Korves TM, Schmid KJ, Caicedo AL, Mays C, Stinchcombe JR, Purugganan MD, Schmitt J. Fitness effects associated with the major flowering time gene FRIGIDA in Arabidopsis thaliana in the field. Am Nat. 2007;169(5):E141-157.

54. Preston JC, Sandve SR. Adaptation to seasonality and the winter freeze. Front Plant Sci. 2013;4:167.

55. Ream TS, Woods DP, Amasino RM. The molecular basis of vernalization in different plant groups. Cold Spring Harb Symp Quant Biol. 2012;77:105-15.

56. Bratzel F, Turck F. Molecular memories in the regulation of seasonal flowering: from competence to cessation. Genome Biol. 2015;16:192.

57. Bastow R, Mylne JS, Lister C, Lippman Z, Martienssen RA, Dean C. Vernalization requires epigenetic silencing of FLC by histone methylation. Nature. 2004:427(6970):164-7.

58. Johanson U, West J, Lister C, Michaels S, Amasino R, Dean C. Molecular analysis of FRIGIDA, a major determinant of natural variation in Arabidopsis flowering time. Science. 2000;290(5490):344-7.

59. Michaels SD, He Y, Scortecci KC, Amasino RM. Attenuation of FLOWERING LOCUS $C$ activity as a mechanism for the evolution of summer-annual flowering behavior in Arabidopsis. Proc Natl Acad Sci U S A. 2003;100(17):10102-7.

60. Werner JD, Borevitz JO, Uhlenhaut NH, Ecker JR, Chory J, Weigel D. FRIGIDAindependent variation in flowering time of natural Arabidopsis thaliana accessions. Genetics. 2005;170(3):1197-207.

61. Cui L, Wall PK, Leebens-Mack JH, Lindsay BG, Soltis DE, Doyle JJ, Soltis PS, Carlson JE, Arumuganathan K, Barakat A, et al. Widespread genome duplications throughout the history of flowering plants. Genome Res. 2006;16(6):738-49.

62. Jiao Y, Wickett NJ, Ayyampalayam S, Chanderbali AS, Landherr L, Ralph PE, Tomsho LP, Hu Y, Liang H, Soltis PS, et al. Ancestral polyploidy in seed plants and angiosperms. Nature. 2011;473(7345):97-100.

63. Jiao Y, Leebens-Mack J, Ayyampalayam S, Bowers JE, McKain MR, McNeal J, Rolf M, Ruzicka DR, Wafula E, Wickett NJ, et al. A genome triplication associated with early diversification of the core eudicots. Genome Biol. 2012;13(1):R3.

64. Van de Peer Y. A mystery unveiled. Genome Biol. 2011;12(5):113.

65. Schlueter JA, Dixon P, Granger C, Grant D, Clark L, Doyle JJ, Shoemaker RC. Mining EST databases to resolve evolutionary events in major crop species. Genome. 2004:47(5):868-76.

66. Pfeil BE, Schlueter JA, Shoemaker RC, Doyle JJ. Placing paleopolyploidy in relation to taxon divergence: a phylogenetic analysis in legumes using 39 gene families. Syst Biol. 2005:54(3):441-54.

67. Bertioli DJ, Moretzsohn MC, Madsen LH, Sandal N, Leal-Bertioli SCM, Guimarães PM, Hougaard BK, Fredslund J, Schauser L, Nielsen AM, et al. An analysis of synteny of Arachis with Lotus and Medicago sheds new light on the structure, stability and evolution of legume genomes. BMC Genomics. 2009;10:45.

68. Cannon SB, Sterck L, Rombauts S, Sato S, Cheung F, Gouzy J, Wang X, Mudge J, Vasdewani J, Schiex T, et al. Legume genome evolution viewed through the Medicago truncatula and Lotus japonicus genomes. Proc Natl Acad Sci U S A. 2006;103(40):14959-64.

69. Cannon SB, llut D, Farmer AD, Maki SL, May GD, Singer SR, Doyle J. Polyploidy did not predate the evolution of nodulation in all legumes. PLoS One. 2010;5:e11630.

70. Lavin M, Herendeen PS, Wojciechowski MF. Evolutionary rates analysis of Leguminosae implicates a rapid diversification of lineages during the tertiary. Syst Biol. 2005;54:575-94. 
71. Karlgren A, Gyllenstrand N, Kallman T, Sundstrom JF, Moore D, Lascoux M, Lagercrantz $U$. Evolution of the PEBP gene family in plants: functional diversification in seed plant evolution. Plant Physiol. 2011;156(4):1967-77.

72. Hedman H, Kallman T, Lagercrantz U. Early evolution of the MFT-like gene family in plants. Plant Mol Biol. 2009;70(4):359-69.

73. Moore RC, Purugganan MD. The evolutionary dynamics of plant duplicate genes. Curr Opin Plant Biol. 2005;8:122-8.

74. De Mita S, Chantret N, Loridon K, Ronfort J, Bataillon T. Molecular adaptation in flowering and symbiotic recognition pathways: insights from patterns of polymorphism in the legume Medicago truncatula. BMC Evol Biol. 2011;11:229.

75. James LC, Tawfik DS. Conformational diversity and protein evolution-a 60year-old hypothesis revisited. Trends Biochem Sci. 2003;28(7):361-8.

76. Kobayashi Y, Kaya H, Goto K, Iwabuchi M, Araki T. A pair of related genes with antagonistic roles in mediating flowering signals. Science. 1999:286(5446):1960-2

77. Hanzawa Y, Money T, Bradley D. A single amino acid converts a repressor to an activator of flowering. Proc Natl Acad Sci U S A. 2005;102(21):7748-53.

78. Ahn JH, Miller D, Winter VJ, Banfield MJ, Lee JH, Yoo SY, Henz SR, Brady RL, Weigel D. A divergent external loop confers antagonistic activity on floral regulators FT and TFL1. EMBO J. 2006;25(3):605-14.

79. Bradley D, Ratcliffe O, Vincent C, Carpenter R, Coen E. Inflorescence commitment and architecture in Arabidopsis. Science. 1997:275(5296):80-3.

80. Tian Z, Wang X, Lee R, Li Y, Specht JE, Nelson RL, McClean PE, Qiu L, Ma J. Artificial selection for determinate growth habit in soybean. Proc Natl Acad Sci U S A. 2010;107(19):8563-8.

81. Ho WW, Weigel D. Structural features determining flower-promoting activity of Arabidopsis FLOWERING LOCUS T. Plant Cell. 2014;26(2):552-64.

82. Manly KF, Robert H, Cudmore J, Meer JM. Map Manager QTX, cross-platform software for genetic mapping. Mamm Genome. 2001;12:930-2.

83. Voorrips RE. MapChart: software for the graphical presentation of linkage maps and QTLs. J Hered. 2002;93:77-8.

84. Altschul SF, Gish W, Miller W, Myers EW, Lipman DJ. Basic local alignment search tool. J Mol Biol. 1990;215:403-10.

85. Kohany O, Gentles AJ, Hankus L, Jurka J. Annotation, submission and screening of repetitive elements in Repbase: RepbaseSubmitter and Censor. BMC Bioinf. 2006;7:474.

86. Lyons E, Pedersen B, Kane J, Alam M, Ming R, Tang H, Wang X, Bowers J, Paterson A, Lisch $D$, et al. Finding and comparing syntenic regions among Arabidopsis and the outgroups papaya, poplar, and grape: CoGe with rosids. Plant Physiol. 2008;148:1772-81.

87. Solovyev V. Statistical approaches in eukaryotic gene prediction. In: Handbook of Statistical Genetics. West Sussex, United Kingdom: John Wiley \& Sons, Ltd; 2004.

88. Kearse M, Moir R, Wilson A, Stones-Havas S, Cheung M, Sturrock S, Buxton S, Cooper A, Markowitz S, Duran C, et al. Geneious Basic: an integrated and extendable desktop software platform for the organization and analysis of sequence data. Bioinformatics. 2012;28:1647-9.

89. Revanna KV, Chiu C-C, Bierschank E, Dong Q. GSV: a web-based genome synteny viewer for customized data. BMC Bioinf. 2011;12:316.

90. Krzywinski M, Schein J, Birol I, Connors J, Gascoyne R, Horsman D, Jones SJ, Marra MA. Circos: an information aesthetic for comparative genomics. Genome Res. 2009;19:1639-45.

91. Li J, Dai X, Liu T, Zhao PX. LegumelP: an integrative database for comparative genomics and transcriptomics of model legumes. Nucleic Acids Res. 2012;40(Database issue):D1221-1229.

92. Katoh K, Misawa K, Kuma K-i, Miyata T. MAFFT: a novel method for rapid multiple sequence alignment based on fast Fourier transform. Nucleic Acids Res. 2002;30:3059-66.

93. Huelsenbeck JP, Ronquist F. MRBAYES: Bayesian inference of phylogenetic trees. Bioinformatics. 2001;17(8):754-5.

94. Librado P, Rozas J. DnaSP v5: a software for comprehensive analysis of DNA polymorphism data. Bioinformatics. 2009;25(11):1451-2.

\section{Submit your next manuscript to BioMed Central and we will help you at every step:}

- We accept pre-submission inquiries

- Our selector tool helps you to find the most relevant journal

- We provide round the clock customer support

- Convenient online submission

- Thorough peer review

- Inclusion in PubMed and all major indexing services

- Maximum visibility for your research

Submit your manuscript at www.biomedcentral.com/submit
) Biomed Central 